\title{
Developments in Computational Fluid Dynamics Modeling of Gasoline Direct Injection Engine Combustion and Soot Emission with Chemical Kinetic Modeling
}

\begin{abstract}
Designed to inject gasoline fuel directly into the combustion chamber, gasoline direct injection (GDI) combustion systems are gaining popularity among the automotive industry. This is because GDI engines offer less pumping and heat losses, enhanced fuel economy and improved transient response. Nonetheless, the technology is often associated with the emission of ultra-fine particulate matter (PM) to the atmosphere. With the increasingly stringent emission regulations, detailed understanding of PM formation within GDI engine configurations is very crucial. To complement the findings based on experimental and optical techniques, computational fluid dynamics (CFD) modeling has been widely utilized to study the in-cylinder physical and chemical events. The success of CFD simulations also requires an accurate representation of gasoline fuel kinetics. Set against the background, the present review reports on the recent developments in chemical kinetic modeling of gasoline fuels and CFD numerical studies for GDI engines emphasizing the combustion and emission stages. Regarding fuel kinetics, the use of primary reference fuel (PRF) and ternary reference fuel (TRF) mechanisms is evaluated. In addition, the current trend portrays a progression towards multi-component surrogate models to account for the complex mixture of practical fuels. It is however observed that many reaction mechanisms proposed in the literature are validated under homogeneous charge compression ignition (HCCI) engine conditions rather than GDI-related ones. CFD modeling of GDI engines typically covers the simulations of spray, mixture formation and combustion processes. Progress in combustion modeling for both homogeneous and stratified charge modes is discussed thoroughly. Still in its infancy, soot modeling studies for GDI engines are reviewed in which several soot models adapted are appraised. The majority of soot models have been previously applied in diesel combustion systems and flame configurations. Significant efforts are currently carried out to improve the model predictions of soot emission from GDI engines.
\end{abstract}




\section{Introduction}

Extensive research and development efforts have been carried out for the past decades to enhance engine performance of automobile vehicles. Significant works of improvement are performed to optimize fuel blends, fuel consumption, engine design, control systems and operating strategies. Among all the technological advances accomplished for internal combustion engines, gasoline direct injection (GDI) engines hold practical potential to achieve a substantial improvement of $5 \%$ to $15 \%$ in fuel economy in the short term [1]. The application of GDI engines penetrated the automotive industry gradually between 1995 and 2005. After 2005, there is an apparent shift towards the new gasoline engine technology among all major car manufacturers globally. In a GDI engine, the fuel is pressurized and injected via a common rail fuel line system directly into the combustion chamber of each cylinder as opposed to the more conventional multi-point port fuel injection (PFI) [2]. The incorporation of direct injection strategy into a spark-ignition engine offers several advantages including enhanced fuel economy, minimized pumping loss, higher compression ratio, reduced knock tendency and improved transient response [3]. The benefits are mainly achieved through the precise control over the amount of fuel and injection timing for good performance and drivability [4]. Characterized by different air-fuel ratios, three combustion modes, namely ultra-lean burn, stoichiometric and full power modes are tailored to specific load conditions [2]. For part load operations, GDI combustion systems are classified into wall-guided, air-guided and spray-guided based on the mechanisms to which an ignitable mixture is formed near spark plug [3], [5]. However, fuel stratification is typically achieved by some combinations of the three approaches with varying relative contributions [3]. Particularly, the spray-guided system has the highest efficiency theoretically with the use of advanced injection technology [6]. In-depth information on GDI technology and its development can be found in a detailed review by Zhao et al. [3].

Over the years, automotive manufacturers have been spending efforts and resources to increase efficiency of GDI engines by reducing fuel consumption and $\mathrm{CO}_{2}$ emission. While momentous success in terms of engine performance is being achieved, continuing research works have, relatively recently, identified GDI engines as an important source of anthropogenic ultra-fine particulate matter (PM) in the atmosphere. For example, the study by Ericsson and Samson [7] demonstrated that PM emission measured experimentally from a GDI engine over the European test cycle consisted of high soot content. Moreover, according to the Particle Measurement Programme, the PM emissions from GDI engines are higher than those of traditional gasoline engines and diesel engines fitted with a diesel particulate filter (DPF) [8]. The increase is generally as much as one order of magnitude compared to PFI engines [9], [10]. Characterized by diameters of less than $100 \mathrm{~nm}$, the airborne ultra-fine particles emitted have been found to affect the respiratory health of adults severely [11]. Furthermore, particle deposition along the respiratory tracts leads to elevated risks for development of asthma, pulmonary inflammation, adverse cardiovascular and neurodegenerative effects as evidenced in recent medical studies [12]-[14]. Increased health risk is often associated with decreasing particle size and increasing concentration.

Consequently, it comes as no surprise that progressively more stringent emission legislations are being implemented to monitor the engine-out exhausts. In Europe, the $5 \mathrm{mg} / \mathrm{km} \mathrm{limit} \mathrm{of} \mathrm{PM} \mathrm{was}$ 
imposed on GDI engines in 2009 under the Euro 5 emission standard. The new Euro 6 standard will further restrict the particulate number emission to be $6 \times 10^{12}$ number $/ \mathrm{km}$ initially and $6 \times 10^{11}$ number $/ \mathrm{km}$ in late 2017 [15]. Despite the internal engine measures for significant PM reductions in GDI engines, experimental particle measurements of exhaust soot by Choi et al. [16] showed that all the current three types of GDI combustion systems failed to adhere to the imposed particle number limits under the Euro 6 standard. In addition, it remains unclear whether further internal engine improvements will suffice to comply with the anticipated emission requirements especially under real world operations. Within the context, detailed understanding of soot formation mechanisms in GDI engines may facilitate the quest for strategy optimization to minimize PM emissions. Correspondingly, numerous related studies have been performed [17][19] while correlations with the various engine operating parameters as well as combustion characteristics were established [20]. Soot formation in GDI engines is often associated with the inherently short time available for fuel vaporization and mixing with air which in turn, causes poor mixture preparation, charge inhomogeneity and liquid impingement of the cylinder walls.

Thus, in order to reap the benefits offered by GDI engines and abide by the strict emission standards simultaneously, in-depth knowledge of complex engine phenomena especially soot processes occurring within GDI engines is crucial to sustain long-term feasibility of the technology. Traditional combustion diagnostics including pressure-based combustion analysis and engine-out emissions measurements provide quantitative data of in-cylinder events in GDI engines. In addition, advanced optical methods such as high-speed imaging [21], two-color pyrometry [22], laser-induced fluorescence [5] and laser-induced incandescence [23] have been widely applied to investigate soot processes within GDI engines. While experimental and optical techniques are developing to capture combustion and emission characteristics of GDI engines, multi-dimensional computational fluid dynamics (CFD) modeling acts as a powerful predictive tool to complement the relevant analyses and studies. Compared to experimental and optical techniques, CFD modeling approach is more cost-effective to investigate engine processes across a wide range of operating conditions and various geometric configurations. The accuracy of numerical results depends on the models selected to represent the in-cylinder events of engine operating cycles. Furthermore, successful combustion simulations also rely on precise descriptions of chemical kinetics of gasoline fuels.

A common and widespread method to model a fully-blended commercial gasoline fuel is through the formulation of a surrogate mixture with limited number of components which emulates physical properties and combustion behavior of the real fuel. The simplest fuel models utilize the single component iso-octane. To better describe gasoline fuels which are typically characterized by octane rating, a binary mixture of primary reference fuels (PRF) consisting of iso-octane and n-heptane is widely used in kinetic studies. Later, deficiencies with PRF mechanisms motivated the inclusion of toluene to account for the aromatics present, leading to the development of toluene reference fuels (TRF) [24]. Due to the expanding knowledge base of fuel kinetics, the use of multi-component fuel surrogates is becoming ubiquitous at the expense of larger size of mechanisms in terms of number of species and reactions. Despite the higher accuracy, kinetic mechanisms with multiple components need the consideration of cross reactions between different fuels with relatively longer computational time. As a result, there is a large pool of 
reaction mechanisms developed for gasoline, each with varying degrees of detail, accuracy and intended applications.

Regarding CFD modeling within GDI engine setups, the emphasis of numerical simulations is to facilitate understandings of spray phenomena, mixture formation, combustion and emission processes in general. Among all, combustion modeling in GDI engines still remains one of the biggest challenges due to the complex interactions between chemistry and turbulence within the combustion chamber. Particularly, higher difficulties occur for stratified-charge combustion which is characterized by a two-stage combustion behavior. It involves a premixed turbulent flame propagation which is then followed by a secondary combustion process [25]. Significant works and improvements have been made to model combustion in GDI engines using various models based on different approaches for treating the flame propagation. Contrariwise, modeling studies on emissions from GDI engines are relatively scarce as compared to those performed on diesel engine combustion systems. Despite the similarities observed for both diesel and gasoline soot, recent studies [26], [27] pinpointed the differences in terms of particle size and number distributions. Such distinctions, along with the relatively new realization that GDI engines are a prominent source of ultra-fine PM and uncertainties in current understanding of the soot formation, are probably the reason why such modeling studies are very limited in the literature.

The central theme of this review lies on the advances and developments in kinetic modeling of gasoline surrogates and CFD modeling of GDI engines emphasizing the stages of combustion and soot emission. The dependency of CFD simulations of engine processes, especially soot modeling, on reaction kinetics in the surrogate mechanisms is depicted in Figure 1. Since an indepth discussion on chemical kinetics of gasoline surrogate mixtures has been provided by Pitz et al. [24], the present review focuses only on the recent progress in the modeling aspect, specifically the development of multi-component reaction mechanisms. The use of PRF and TRF mechanisms to represent practical gasoline fuels is appraised, highlighting the importance to include aromatic fuel species for soot prediction. In addition, the significance of cross reactions between different fuel components to be included in the kinetic models is discussed. Recognizing the importance of GDI engine technology for future automobile industry, this review also concentrates on the research efforts to date in the field of CFD simulations, particularly combustion and soot emission modeling. Progress in modeling the combustion process in GDI engines for both homogenous and stratified charges is summarized along with the relevant CFD sub-models applied. Several reviews [28]-[30] have been published to discuss the soot phenomena studies conducted for diesel engine combustion. To the authors' best knowledge, a study consolidating the current state-of-the-art in modeling of soot processes within gasoline engines, particularly GDI engine configurations has yet to be reported. Therefore, the last section of this review discusses the available numerical studies on soot modeling in GDI engines by examining the soot models adapted and their corresponding soot emission predictions. At the same time, the incorporation of chemical kinetic models to enable computation of soot precursor species for soot nucleation is also elaborated. 


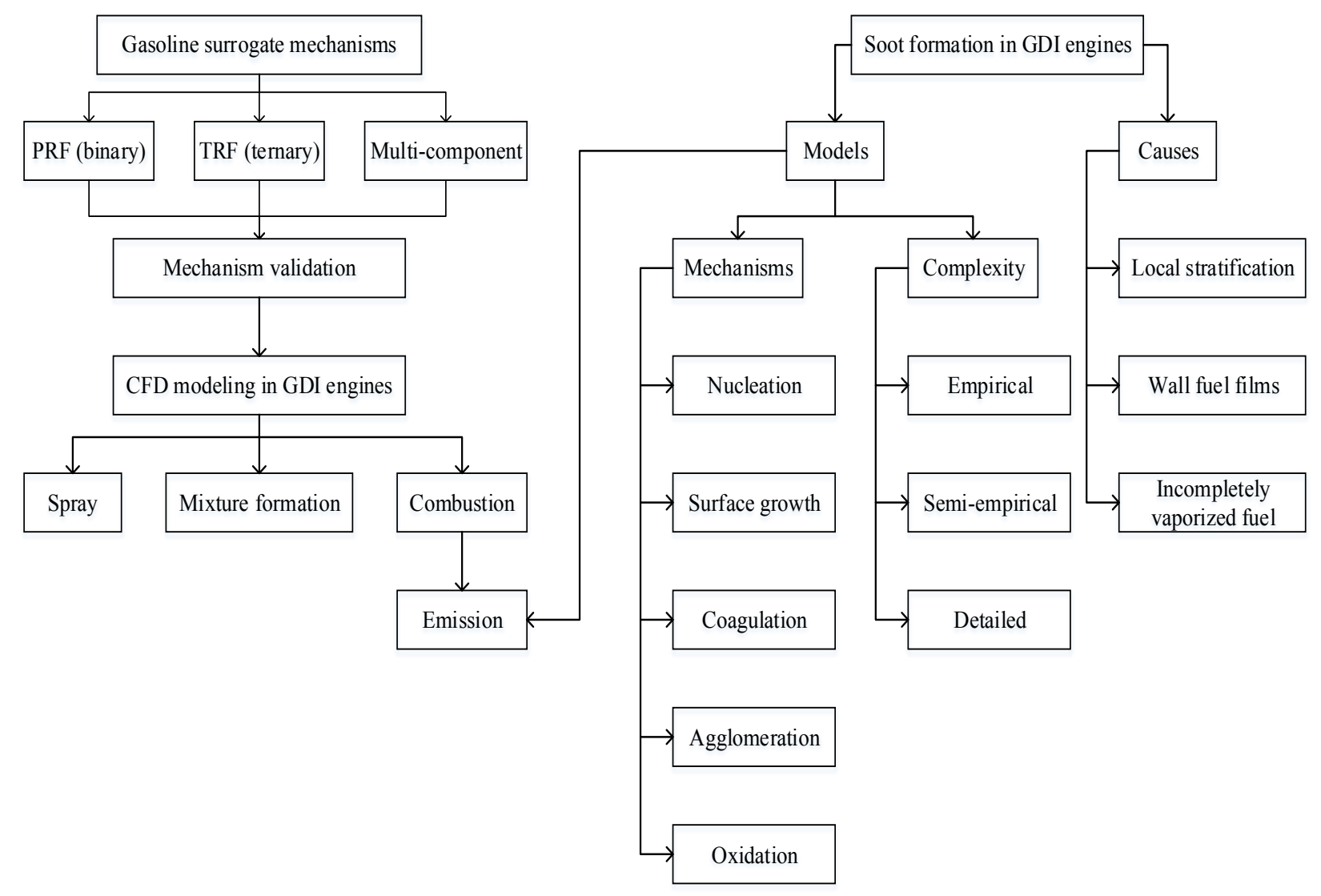

Figure 1 Flowchart showing the influence of chemical kinetic mechanisms of gasoline fuel on CFD modeling in GDI engines particularly soot processes.

\section{Chemical Kinetic Modeling of Gasoline Surrogates}

Gasoline fuel is a complex mixture which consists of various hydrocarbon constituents, ranging from linear and branched chain aliphatic compounds to aromatics. The boiling range components mainly consist of paraffins, naphthenes (cycloparaffins) and aromatics. Additional processing and upgrading are necessary to enable its utilization in combustion engines. Typically, olefins are produced at the refinery and blended into the finished fuel in order to increase the octane rating [24]. A large variation in gasoline composition is observed across the market fuels, as illustrated in Table 1, which can be attributed to differences in crude sources as well as the relevant refinery, blending and finishing processes involved.

Table 1 Approximate ranges of hydrocarbons found in commercial U.S. gasoline [24].

\begin{tabular}{lc}
\hline Hydrocarbon class & Volume percentage (\%) \\
\hline Paraffins & $32-80$ \\
Naphthenes & $2-10$ \\
Olefins & $2-18$ \\
Aromatics & $10-44$ \\
\hline
\end{tabular}

The combustion behavior exhibited by gasoline in engine applications can be observed through the integration of CFD tools and chemical kinetic models. However, due to the lack of 
understanding in the reaction kinetics of all gasoline components as well as their chemical interactions among one another, it is therefore not possible to model full blend gasoline in detailed kinetic studies currently. Also, the associated computational efforts and cost in modeling full gasoline is impractical [31]. Therefore, it is common practice to develop surrogate mixtures which are capable of mimicking the actual behavior of real fuels through simplified representations with limited number of components. The surrogate models are formulated in such a way that the physical properties and combustion behavioral targets such as composition, bulk burn duration and emissions can be reproduced with reasonable accuracy [24]. In fact, a chemical kinetic mechanism for these surrogate mixtures should retain its high-fidelity to model individual fuel components apart from being capable to emulate the combustion characteristics of practical fuels appropriately [32].

In developing the surrogate fuels, the approach utilized widely involves identifying an individual species for each class of hydrocarbon present, with the assumption that its kinetic behavior resembles others having similar chemical structure. The selection of representative species and its respective proportion depends primarily on the targets or properties required to be predicted successfully over a range of operating conditions for certain target fuels in the market. On the other hand, the decision on the suitable set of targets relies on the specific type of engine application such as PFI spark ignition (SI), homogenous charge compression ignition (HCCI) and direct injection spark ignition (DISI) or GDI, together with the potential operating environment [24]. For instance, matching the reactivity of the fuel in a certain set of operating conditions is a common way in surrogate formulation. Apart from ignition properties, matching other aspects like distillation curve, flame development and propagation as well as sooting tendency is important to ensure the effectiveness of surrogate mixtures developed [33].

\subsection{Development of Gasoline Surrogate Mechanisms}

The development of chemical kinetic models and experimental work for gasoline surrogate fuels was reviewed extensively by Pitz et al. [24], targeting HCCI engine combustion. The significance to select suitable targets to be reproduced based on the intended applications was also highlighted. Simmie [34] provided an in-depth discussion about detailed chemical mechanisms for the intermediate to high-temperature combustion of hydrocarbons including alkanes, alkenes, dienes, alkynes and aromatics, whereas Battin-Leclerc's review [35] focused on those for low-temperature combustion of hydrocarbons which serve as potential fuel components for gasoline and diesel surrogate mixtures, together with a comprehensive compilation of relevant experimental results. The following discussion emphasizes the more recent kinetic modeling studies of gasoline surrogate fuels through the inclusion of multiple representative fuel components.

For gasoline, the simplest fuel models contain only a single component of iso-octane, and are applied in flame propagation studies [36]. Moreover, due to the simplification it brings, this approximation is commonly accepted in CFD simulations of GDI engines [37], [38] and has produced reasonable results. However, several modeling studies [32], [39] questioned the reliability of using iso-octane alone as gasoline surrogates. This is primarily attributed to the obvious fact that the octane number $(\mathrm{ON})$ of iso-octane is 100 [40] which is relatively higher than that of typical gasoline [41]. The more widespread approach in formulating gasoline surrogates is based on the binary blends of iso-octane and n-heptane which was first proposed by Edgar [42] to measure knock characteristics of commercial gasoline. The two paraffinic 
hydrocarbons form the PRF and establish the scale of octane rating for gasolines. By definition, $\mathrm{ON}$ is the percentage by volume of iso-octane in a PRF mixture which just causes engine knock in standardized tests as the real fuel does under identical operating conditions [43]. Therefore, PRF mixtures are applied to represent gasoline fuels with different $O N$ by varying the proportions of the binary blends.

The two octane scales characterizing the knock behavior of gasoline are research octane number $(\mathrm{RON})$ and motor octane number $(\mathrm{MON})$ which are determined from the standardized research method [44] and motor method [45] tests respectively, using the cooperative fuel research (CFR) engine. While PRF mixtures continue to be a popular surrogate option to model real gasoline fuels, the associated deficiencies begin to surface during applications involving more complex engine phenomena found in SI and HCCI engines. Unlike simple PRF, practical gasoline possesses a quasi-continuous spectrum of hydrocarbon constituents with dissimilar RON and MON values. The difference between RON and MON is termed fuel sensitivity which is zero for a PRF fuel. On the other hand, actual fuels for SI engines normally have fuel sensitivity ranging from 7 to 12 [41]. Additionally, typical engine operating parameters such as pressure and temperature deviate from those employed in the CFR tests [46], causing RON and MON to be incomplete indicators for real-life knock resistance and, more in general, engine performance.

As a result, the octane index (OI) has been introduced as a more realistic description of the true auto-ignition resistance of fuels [46]. OI is expressed in the following equation, where $\mathrm{K}$ is a constant depending on engine design and operating conditions:

$$
O I=(1-K) R O N+K \times M O N
$$

By definition, $\mathrm{K}$ is zero for RON condition and becomes unity at MON condition [43]. Similar to $\mathrm{ON}$, higher OI gives rise to greater auto-ignition resistance, thus better anti-knock quality of the fuel. A detailed review investigating the auto-ignition quality of fuels in terms of OI and $\mathrm{K}$ was provided by Kalghatgi [41] in which a monotonic decrease in the average value of $\mathrm{K}$ was reported between year 1987 and 1992, owning to engine modifications such as higher compression ratios, downsizing and turbocharging.

The limitations of PRF mixtures drive researchers in the combustion community to look into the development of complex reaction mechanisms with more fuel components so as to better emulate the exact composition and combustion characteristics of real fuels. Within this context, the inclusion of a fuel component in the surrogate models to account for the aromatic content is becoming increasingly important. Being the most abundant aromatic in gasoline (up to 35\%), toluene is typically selected as the representative fuel species [24]. Furthermore, the chemistry of aromatics is crucial for examining the formation of soot in internal combustion engines as demonstrated in several studies [47]-[49] which correlated sooting tendency to the amount of aromatic rings present. The addition of toluene into the PRF mechanisms leads to the establishment of TRF models. Since toluene has a RON of 120 and a MON of 109 [43], ternary blends of TRF allow the formulation of surrogate mixtures with intended fuel sensitivities, thus better resembling the properties of real gasoline. In fact, the application of TRF as surrogates is in line with the recommendations given by Pitz et al. [24] for short-term development on chemical kinetic modeling of gasoline. Hence, the current trend observes a shift of focus from PRF to TRF surrogate models as the latter better resembles real gasoline fuels available 
commercially. The advantages and disadvantages of PRF and TRF mechanisms are summarized in Table 2.

Table 2 Advantages and disadvantages of PRF and TRF reaction mechanisms.

\begin{tabular}{|c|c|c|}
\hline Mechanisms & Advantages & Disadvantages \\
\hline PRF & $\begin{array}{ll} & \text { Simpler binary fuel models } \\
\text { - } & \text { Direct representation of octane rating } \\
\text { - } & \text { Well-established chemical reaction } \\
\text { mechanisms } & \\
\text { - } & \text { Extensive experimental data for validation }\end{array}$ & $\begin{array}{l}\text { - } \text { Match RON or MON but not both } \\
\text { - Represent linear and branched paraffins } \\
\text { only } \\
\text { - Inappropriate for complex engine } \\
\text { phenomena deviated from standardized } \\
\text { tests }\end{array}$ \\
\hline TRF & $\begin{array}{ll}\text { - } & \text { Varied RON and MON to account for fuel } \\
\text { sensitivity } \\
\text { - } \\
\text { Include representation of aromatics in real } \\
\text { fuels } \\
\text { - } \quad \text { Improve prediction of soot emission } \\
\text { Emulate physical properties of fuels (e.g. } \\
\text { H/C ratio) }\end{array}$ & $\begin{array}{l}\text { - Larger ternary fuel models } \\
\text { - Lack of understanding in toluene } \\
\text { mechanism } \\
\text { - Need to consider cross reactions between } \\
\text { alkanes and aromatics } \\
\text { - Limited experimental data for a wide range } \\
\text { of operating conditions }\end{array}$ \\
\hline
\end{tabular}

More recently, with detailed information gained on the chemistry and new experimental works performed for other hydrocarbons present in gasoline fuels, chemical modelers have extended the complexity of kinetic models by merging those representative of naphthenes, olefins and oxygenates. Consequently, apart from TRF, numerous quaternary, quinary and multi-component reaction mechanisms are extensively constructed and developed with the ultimate goal to provide the best representation of fully blended gasoline fuels. Table 3 shows a bibliographic compilation of the available tri- and multi-component fuel models, to the authors' best knowledge, which are applied as gasoline surrogates. The validation criteria and relevant testing conditions involving ternary and/or multi-component mixtures as well as real gasoline fuels are tabulated along. For brevity, the validation conditions based on single-component fuels (neat hydrocarbons) and binary fuel blends are not reported in Table 3. It is observed that most, if not all, of the surrogate models are validated against relevant experimental data of pure and binary mixtures of isooctane, n-heptane and/or toluene in general. Such validation studies help to ensure the robustness of fuel mechanisms across varying compositions and retain their predictive capability for each respective single fuel component making up the multi-component models [32]. 
Table 3 Bibliographic compilation of the available multi-component surrogate mechanisms for gasoline.

\begin{tabular}{|c|c|c|c|c|c|c|c|c|}
\hline \multirow[t]{2}{*}{ Year } & \multirow[t]{2}{*}{ Author(s) } & \multirow[t]{2}{*}{ Structure } & \multirow[t]{2}{*}{$\mathrm{N}_{\mathrm{S}}$} & \multirow[t]{2}{*}{$\mathrm{N}_{\mathrm{R}}$} & \multicolumn{4}{|c|}{ Validation conditions } \\
\hline & & & & & Criterion & $\mathrm{T}(\mathrm{K})$ & $\mathrm{p}$ (bar) & $\varphi$ \\
\hline \multicolumn{9}{|c|}{ Tri-component TRF mechanisms } \\
\hline 2000 & Nakano et al. [50] & Detailed & 782 & 3631 & $\mathrm{HCCI}^{\mathrm{a}}$ & $490^{\mathrm{b}}$ & - & 0.39 \\
\hline 2002 & $\begin{array}{l}\text { Ogink and Golovitchev } \\
\text { [51] }\end{array}$ & Reduced & 109 & 506 & $\mathrm{HCCI}^{\mathrm{a}, \mathrm{c}}$ & $\begin{array}{l}469, \\
482^{\mathrm{b}}\end{array}$ & $1.9,2.4,3.8^{\mathrm{b}}$ & $\begin{array}{ll}0.64, & 0.82, \\
1.01 & \\
\end{array}$ \\
\hline 2007 & Andrae et al. [52] & Detailed & 1083 & 4635 & $\mathrm{ST}^{\mathrm{d}}$ & $850-1280$ & 55 & 1 \\
\hline 2007 & Chaos et al. [53] & Reduced & 469 & 1221 & $\begin{array}{l}\mathrm{S}_{\mathrm{L}}{ }^{\mathrm{e}} \\
\mathrm{VPFR}^{\mathrm{f}} \\
\mathrm{ST}^{\mathrm{d}}\end{array}$ & $\begin{array}{l}400,550 \\
550-950 \\
850-1280\end{array}$ & $\begin{array}{l}1 \\
12.5 \\
20,55\end{array}$ & $\begin{array}{l}0.6-1.4 \\
1 \\
0.5,1,2\end{array}$ \\
\hline 2008 & Andrae et al. [54] & Reduced & 137 & 633 & $\begin{array}{l}\mathrm{ST}^{\mathrm{d}} \\
\mathrm{RCM}^{\mathrm{d}} \\
\mathrm{S}_{\mathrm{L}}{ }^{\mathrm{e}} \\
\mathrm{HCCI}^{\mathrm{a}}\end{array}$ & $\begin{array}{l}850-1280 \\
318 \\
353,500 \\
353,523^{\mathrm{b}}\end{array}$ & $\begin{array}{l}30.4,50.7 \\
1 \\
1 \\
1,2^{b}\end{array}$ & $\begin{array}{l}1 \\
0.4 \\
0.7-1.3 \\
0.25\end{array}$ \\
\hline 2009 & Anderlohr et al. [55] & Detailed & 536 & 3000 & $\begin{array}{l}\mathrm{RCM}^{\mathrm{g}} \\
\mathrm{ST}^{\mathrm{d}}\end{array}$ & $\begin{array}{l}318 \\
850-1100\end{array}$ & $\begin{array}{l}10 \\
12-25,45-60\end{array}$ & $\begin{array}{l}0.4 \\
1\end{array}$ \\
\hline 2009 & Cancino et al. [56] & Detailed & 1053 & 4277 & $\mathrm{ST}^{\mathrm{d}}$ & $850-1280$ & 25,55 & 1 \\
\hline 2009 & Sakai et al. [57] & Detailed & 783 & 2883 & $\begin{array}{l}\text { ST }^{\mathrm{d}} \\
\text { VPFR }^{\mathrm{f}}\end{array}$ & $\begin{array}{l}850-1280 \\
550-950\end{array}$ & $\begin{array}{l}25,50 \\
12.5\end{array}$ & $\begin{array}{l}1 \\
1\end{array}$ \\
\hline 2009 & Machrafi et al. [58] & Reduced & 49 & 62 & $\begin{array}{l}\mathrm{ST}^{\mathrm{d}} \\
\mathrm{HCCI}^{\mathrm{a}} \\
\end{array}$ & $\begin{array}{l}850-1280 \\
343^{\mathrm{b}}\end{array}$ & $\begin{array}{l}20,55 \\
- \\
\end{array}$ & $\begin{array}{l}0.5,1 \\
0.462 \\
\end{array}$ \\
\hline 2010 & Lee et al. [59] & Reduced & 48 & 67 & $\begin{array}{l}\mathrm{ST}^{\mathrm{d}} \\
\mathrm{RCM}^{\mathrm{g}}\end{array}$ & $\begin{array}{l}850-1280 \\
293,323\end{array}$ & $\begin{array}{l}18,50 \\
0.48\end{array}$ & $\begin{array}{l}0.5,1,2 \\
1\end{array}$ \\
\hline 2011 & Zhang et al. [60] & Reduced & 70 & 196 & $\begin{array}{l}\mathrm{ST}^{\mathrm{d}} \\
\mathrm{HCCI}^{\mathrm{a}}\end{array}$ & $\begin{array}{l}850-1200 \\
435,489^{b}\end{array}$ & $\begin{array}{l}30.4 \\
1.5,3.3^{b}\end{array}$ & $\begin{array}{l}1 \\
0.25 \\
\end{array}$ \\
\hline 2012 & Raj et al. [61] & Reduced & 226 & 2121 & $\begin{array}{l}\text { PREMIX }^{\mathrm{f}} \\
\text { OPPDIF }^{\mathrm{f}}\end{array}$ & $\begin{array}{ll}- \\
- \\
\end{array}$ & $\begin{array}{ll}1 \\
- \\
\end{array}$ & $\begin{array}{l}1.8-3.06 \\
- \\
\end{array}$ \\
\hline 2013 & Liu et al. [62] & Reduced & 56 & 168 & $\begin{array}{l}\mathrm{ST}^{\mathrm{d}} \\
\mathrm{S}_{\mathrm{L}}{ }^{\mathrm{e}} \\
\mathrm{HCCI}^{\mathrm{a}}\end{array}$ & $\begin{array}{l}850-1280 \\
353,373,500 \\
523^{\mathrm{b}}\end{array}$ & $\begin{array}{l}15-25,45-60 \\
1,10-25 \\
1^{\mathrm{b}}\end{array}$ & $\begin{array}{l}0.5,1,2 \\
0.7,1.3 \\
0.2857\end{array}$ \\
\hline 2014 & Ranzi et al. [63] & Reduced & 156 & 3370 & $\begin{array}{l}\mathrm{ST}^{\mathrm{d}} \\
\mathrm{S}_{\mathrm{L}}^{\mathrm{e}} \\
\end{array}$ & $\begin{array}{l}850-1280 \\
298,358 \\
\end{array}$ & $\begin{array}{l}15,50 \\
1\end{array}$ & $\begin{array}{l}1 \\
0.7-1.3 \\
\end{array}$ \\
\hline 2014 & Niemeyer and Sung [64] & Reduced & $386^{\mathrm{h}} / 276^{\mathrm{i}}$ & $1591^{\mathrm{h}} / 936^{\mathrm{i}}$ & $\begin{array}{l}\text { Auto-ignition } \\
\text { PSR }^{\mathrm{j}} \\
\mathrm{S}_{\mathrm{L}}{ }^{1} \\
\mathrm{HCCI}^{\mathrm{m}}\end{array}$ & $\begin{array}{l}700-1600 \\
300 \\
450 \\
421-489 \\
\end{array}$ & $\begin{array}{l}1-20 \\
1,20 \\
1,20 \\
1.5-3.3 \\
\end{array}$ & $\begin{array}{l}0.5-1.5 \\
0.5-1.5 \\
0.6-1.4 \\
0.5,0.75 \\
\end{array}$ \\
\hline 2014 & Niemeyer and Sung [64] & Reduced & $199^{\mathrm{h}} / 173^{\mathrm{i}}$ & $1011^{\mathrm{h}} / 689^{\mathrm{i}}$ & $\begin{array}{l}\text { Auto-ignition }{ }^{\mathrm{j}} \\
\mathrm{PSR}^{\mathrm{k}} \\
\mathrm{S}_{\mathrm{L}}{ }^{1}\end{array}$ & $\begin{array}{l}1000-1600 \\
300 \\
450\end{array}$ & $\begin{array}{l}1-20 \\
1,20 \\
1,20\end{array}$ & $\begin{array}{l}0.5-1.5 \\
0.5-1.5 \\
0.6-1.4\end{array}$ \\
\hline 2015 & Zheng and Lv [65] & Reduced & 80 & 184 & $\mathrm{ST}^{\mathrm{d}}$ & $850-1250$ & $30.4,50.7$ & 1 \\
\hline 2015 & Wang et al. [66] & Reduced & 109 & 543 & $\mathrm{ST}^{\mathrm{d}}$ & $850-1280$ & 20,50 & 1 \\
\hline 2015 & An et al. [67] & Reduced & 219 & 1229 & $\begin{array}{l}\mathrm{ST}^{\mathrm{d}} \\
\mathrm{S}_{\mathrm{L}}{ }^{\mathrm{e}} \\
\text { PREMIX }^{\mathrm{f}} \\
\text { OPPDIF }^{\mathrm{f}}\end{array}$ & $\begin{array}{l}850-1280 \\
338,358 \\
- \\
-\end{array}$ & $\begin{array}{l}15-25,45-60 \\
1 \\
1 \\
-\end{array}$ & $\begin{array}{l}0.5,1,2 \\
0.8-1.3 \\
1.9,1.97 \\
-\end{array}$ \\
\hline Four-c & mponent mechanisms & & & & & & & \\
\hline 2007 & Yahyaoui et al. [68] & Detailed & 234 & 1860 & $\begin{array}{l}\mathrm{JSR}^{\mathrm{f}} \\
\mathrm{ST}^{\mathrm{d}} \\
\end{array}$ & $\begin{array}{l}800-1130 \\
1390-1880 \\
\end{array}$ & $\begin{array}{l}10 \\
2-10 \\
\end{array}$ & $\begin{array}{l}1 \\
1 \\
\end{array}$ \\
\hline 2008 & Golovitchev et al. [69] & Reduced & 129 & 700 & $\begin{array}{l}\mathrm{ST}^{\mathrm{d}} \\
\mathrm{ST}^{\mathrm{n}}\end{array}$ & $\begin{array}{l}850-1670 \\
850-1280\end{array}$ & $\begin{array}{l}1.82-2.14, \\
25,45-60 \\
54\end{array}$ & $\begin{array}{l}1 \\
1\end{array}$ \\
\hline 2009 & Cancino et al. [56] & Detailed & 1085 & 4748 & $\mathrm{ST}^{\mathrm{n}}$ & $690-1200$ & $10,30,50$ & 1 \\
\hline 2009 & Bieleveld et al. [70] & Reduced & 311 & $>8000$ & $\begin{array}{l}\text { Non- } \\
\text { premixed } \\
\text { flame }^{\circ}\end{array}$ & 298,468 & 1 & - \\
\hline 2010 & Huang et al. [71] & Reduced & 120 & 677 & $\begin{array}{l}\mathrm{ST}^{\mathrm{d}} \\
\mathrm{ST}^{\mathrm{n}} \\
\mathrm{S}_{\mathrm{L}}{ }^{\mathrm{e}}\end{array}$ & $\begin{array}{l}806-1670 \\
600-1250 \\
298, \quad 350, \\
353,373,500\end{array}$ & $\begin{array}{l}2,15-25,45-60 \\
20 \\
1,10-25\end{array}$ & $\begin{array}{l}0.5,1,2 \\
1 \\
0.5-1.8\end{array}$ \\
\hline 2011 & Mehl et al. [72] & Detailed & 1389 & 5935 & $\begin{array}{l}\mathrm{RCM}^{\mathrm{d}} \\
\mathrm{JSR}^{\mathrm{f}} \\
\end{array}$ & $\begin{array}{l}600-900 \\
800-1880 \\
\end{array}$ & $\begin{array}{l}11.8-14.8 \\
10 \\
\end{array}$ & $\begin{array}{l}1 \\
1 \\
\end{array}$ \\
\hline 2011 & Mehl et al. [33] & Reduced & 312 & 1488 & $\begin{array}{l}\text { Auto-ignition } \\
\mathrm{S}_{\mathrm{L}}^{\mathrm{j}}\end{array}$ & $\begin{array}{l}650-1300 \\
323,348,373 \\
\end{array}$ & $\begin{array}{l}10,20,40,80 \\
1,10-25\end{array}$ & $\begin{array}{l}0.3,1 \\
0.6-1.4 \\
\end{array}$ \\
\hline 2013 & Wang et al. [73] & Reduced & 473 & 1267 & $\mathrm{~S}_{\mathrm{L}}{ }^{\mathrm{e}}$ & 353,500 & $1,10-25$ & $0.5-1.7$ \\
\hline
\end{tabular}


computational cost scales cubically with the number of species, thus causing the application of large mechanisms intractable based on the current computing capacity [88]. Therefore, there is a variety of mechanism reduction methods and schemes proposed including rate analysis for flame modeling [89], directed relation graph [90], generic algorithm [91] and simulation error minimization [92], among others which are tailored for intended applications. The reduction of different chemical kinetic mechanisms has been reviewed in several publications [88], [93], [94].

\subsection{TRF Kinetic Mechanisms}

Early applications of tri-component TRF surrogate models were seen in modeling works of HCCI engines to study the effect of exhaust gas recirculation (EGR) on ignition control [50] and simulate the combustion process through a multi-zone model [51]. Constructed by adding toluene oxidation mechanism to the base model of paraffinic hydrocarbons, the models lacked validations from more complex fuel blends of gasoline. The TRF kinetic model developed by Andrae et al. [52] comprised 1083 species within 4635 reactions by incorporating the toluene sub-mechanism of Sivaramakrishnan et al. [95] into the PRF model by Lawrence Livermore National Laboratory (LLNL) [96]. This highly detailed mechanism was evaluated against ID times and species profiles from ST as well as auto-ignition conditions under HCCI engine configurations and was widely utilized in successive studies on chemical kinetics of gasoline [56], [59], [62]. In their model, Andrae et al. [52] included cross reactions between different fuel components, despite their trivial effects on the auto-ignition delays in ST experiments, arguing that their importance might dominate under auto-ignition processes in an internal combustion engine.

Later, Andrae et al. [54] integrated the skeletal mechanisms of PRF into a detailed chemical model of toluene in order to formulate a semi-detailed TRF model with 137 species and 633 reactions, a significantly smaller size as compared to the previous detailed model [52]. Particularly, the introduction of cross reactions between benzylperoxy radicals and n-heptane enhanced model performance for a binary blend of n-heptane and toluene at temperatures below $800 \mathrm{~K}$. The works by Andrae et al. [52], [54], indeed highlighted the need to consider cross reactions among different fuels in TRF reaction mechanisms. On the contrary, Chaos et al. [53] refuted the significance of co-oxidation or cross reactions by pointing out that the coupling between toluene and PRF involved only a small radical pool without participation of large radical species. They associated the discrepancies in Andrae et al.'s model [52] with insufficiency of the toluene sub-mechanism at high pressures which could not be compensated by inclusion of cross reactions. Thus, starting from the baseline model by Klotz et al. [97], substantial efforts were aimed at improving toluene kinetics to develop an in-house submechanism. The resulting detailed kinetic mechanism for TRF without cross reactions possessed 469 species and 1221 reactions and underwent additional validation against reactivity profiles during oxidation in a VPFR from 500 to $1000 \mathrm{~K}$ [53].

However, Sakai et al. [57] discovered the acceleration effect in ID with toluene addition to isooctane at high temperatures in an earlier shock tube study [98] and increase in ID of n-heptane by adding toluene. Suggesting that cross reactions between alkenes and aromatics were responsible for such observations, they investigated the kinetic interactions between PRF and toluene to formulate a detailed chemical model containing 783 species and 2883 reactions. Reaction path and sensitivity analysis revealed that reactions between allene and benzyl radical and those between alkenes and aromatic radicals were dominant cross reactions [57]. Anyhow, 
further examinations on alkene reactions with aromatic, both theoretically and experimentally, are suggested to be necessary. On the other hand, the detailed TRF mechanism assembled by Cancino et al. [56] did not consider the cross reactions proposed by Andrae et al. [52]; they claimed that the reactions were insignificant in predicting ID times in ST at 25 bar and 55 bar. Overall, while the trends were correctly reproduced, the model over-predicted ID times across the temperature range of 690-1200 $\mathrm{K}$ [56]. In modeling the impact of nitric oxides $\left(\mathrm{NO}_{\mathrm{x}}\right)$ on gasoline fuel oxidation, Anderlohr et al. [55] developed a detailed TRF kinetic mechanism which incorporated cross reactions as well as coupling reactions between hydrocarbons and $\mathrm{NO}_{\mathrm{x}}$. Good agreement was observed between model predictions and experimental measurements of coolflame and main-flame ID in HCCI engines and species concentration profiles under jet-stirred reactor (JSR) conditions diluted by varying $\mathrm{NO}$ concentrations. Likewise, the effect of $\mathrm{NO}_{\mathrm{x}}$ was studied by Zheng and Lv [65] with a simplified mechanism containing 80 species and 184 reactions. Predictions of pressure profiles and combustion phases were good over the NO range of 0-500 ppmv in HCCI engines.

Recently, the imperative need to gain deeper understanding about chemical kinetics and feasible computational modeling of gasoline combustion within complex engine phenomena drives the expansive development of relatively reduced ternary reaction mechanisms for TRF [58]-[60], [62]-[66]. Generally, the validations of reduced models are extensive and thorough in which crucial targets such as ID times, flame speeds and species profiles were reproduced with reasonable accuracy for neat hydrocarbons, binary blends, ternary surrogate mixtures and real gasoline fuels across a wide range of operating conditions pertinent to those of internal combustion engines. Furthermore, most of the reduced ternary models [58]-[60], [62], [65] were formulated with the goal to model gasoline combustion in HCCI mode as the auto-ignition characteristics are dependent primarily on fuel chemical kinetics under the specific operating conditions [51]. Niemeyer and Sung [64] performed skeletal mechanism reductions on TRF for comprehensive $(700-1600 \mathrm{~K})$ and high-temperature $(1000-1600 \mathrm{~K})$ ranges, respectively at two levels of accuracy (10\% and 30\% error limits). The resulting models were successful in reproducing ID times, temperature response curves in perfectly stirred reactor (PSR), laminar flame speeds and major species concentrations under HCCI simulations when compared with the parent detailed mechanism. Their work also recommended reduction through multi-component fuel model altogether over combination of reduced mechanisms of individual neat fuel components. This is because the latter led to a larger kinetic mechanism with the loss of important cross reactions.

The understanding of soot processes within internal combustion engines has always been at the center of attention in the combustion community as a consequence of increasing health and environmental concerns, along with the implementation of more stringent emission regulations across the globe. In this context, polycyclic aromatic hydrocarbons (PAH) are inferred to be the presumed soot precursors whereby the incipient of a soot particle occurs by the collision of two PAH molecules [99]. Detailed information on PAH formation and their sequential growth to soot was discussed by Richter and Howard [100]. Recognizing the contribution of PAH chemistry, Raj et al. [61] incorporated PAH sub-mechanisms up to coronene $\left(\mathrm{A}_{7}\right)$ to formulate a kinetic model for gasoline surrogate fuels possessing 226 species and 2121 reactions. The mechanism was validated in the premixed laminar flames (PREMIX) and counter-flow or opposed-flow diffusion flames (OPPDIF). Additionally, the reaction mechanism was capable to capture the experimentally observed synergistic effect on PAH formation for fuel mixtures of $\mathrm{n}$ - 
heptane/toluene and iso-octane/toluene, an improvement over the previous related mechanisms developed by Blanquart et al. [101] and Marchal et al. [102], respectively. Chemistry of lowtemperature combustion and validations of ID times and flame speeds were, however, left out in the study. In order to overcome these limitations, An et al. [67] updated Raj et al.'s work [61] to develop a new TRF-PAH mechanism with 219 species and 1229 reactions which covered additional validations of ID in ST and flame propagation speeds for gasoline. For the similar purpose of PAH and soot predictions, a further reduced mechanism containing 109 species and 543 reactions was proposed by Wang et al. [66] to allow feasible application in engine simulations. Extensive validations were performed including ID, flame speeds, species profiles as well as combustion in HCCI and direct injection compression ignition engines.

\subsection{Multi-component Kinetic Mechanisms}

While massive efforts are still directed at exploring the chemical kinetics of TRF, many are now seeking other potential components to develop more complex fuel models which parallels the concurrent works in blending gasoline with various fuel additives to boost up the performance of combustion devices, specifically combustion engines. As a result, four-, five- and multicomponent chemical mechanisms are published in the literature, which incorporate different hydrocarbon classes present in gasoline fuels including cycloalkanes, alkenes and oxygenates. Bieleveld et al. [70] selected methylcyclohexane $(\mathrm{MCH})$ to represent the family of naphthenes in the quaternary chemical mechanism to model the critical conditions of extinction and autoignition of gasoline fuels in non-premixed flows which are relevant to GDI engine applications. Meanwhile, to account for the olefinic content, potential candidates employed to be representative species are 1-hexene, 2-pentene and diisobutylene (DIB). A detailed kinetic model assembled based on LLNL's mechanisms was applied by Mehl et al. [72] to simulate the combustion of surrogate mixtures made of iso-octane, n-heptane, toluene and 1-hexene. Consisting of 1389 species and 5935 reactions, the mechanism was validated at stoichiometric condition against experimental data from RCM, ST and JSR at pressures from 3 to 50 atm and a temperature range of 650-1200 K. In a following study [33], a reduced version with 312 species and 1488 reactions was presented, targeting a surrogate mixture of TRF/2-pentene with satisfactory model predictions of ID and flame speeds. Based on the similar four-component surrogate, the detailed model [72] was greatly reduced by Niemeyer and Sung [75] to 148 species for low-temperature HCCI-like conditions (750-1200 K) and 79 species for hightemperature SI/CI-like conditions (1000-1400 K). Comparisons of ID, temperature profiles, PSR temperature response curves, extinction turning points and laminar flame speeds demonstrated an error limit of $10 \%$. DIB was chosen as the fourth component to represent alkenes in the chemical mechanisms developed by Wang et al. [73] and Zheng and Liang [76]. In particular, Wang et al.'s study [73] suggests the reactions between allene and benzyl radical are unimportant to describe the kinetic interactions, opposing the earlier claim put forward by Sakai et al. [57]. A very recent reduced model of TRF/DIB which included 103 species among 199 reactions was constructed by Zheng and Liang [76] for HCCI combustion.

Currently, the use of gasoline blended with various oxygenates as fuel additives is becoming more widespread in which ethanol is identified as the most prevalent blend component. This is because the leveraged use of ethanol in boosted engine concept allows lowered fuel consumption and corresponding emissions by about 25\% [103]. Golovitchev et al. [69] merged a TRF surrogate model with a reduced mechanism for ethanol combustion with a total of 129 species and 700 reactions for modeling an ethanol boosted gasoline engine. A detailed kinetic model of 
TRF/ethanol containing 1085 species and 4748 reactions was assembled by Cancino et al. [56] to simulate ID in ST at pressures of 10, 30 and 50 bar and temperatures of 690 to $1200 \mathrm{~K}$. However, over-predictions of ID were observed particularly at the low-temperature regime. Furthermore, the semi-detailed chemical mechanism developed by Huang et al. [71] was validated against experimental ID and flame velocities of gasoline fuels and blends. They concluded that an increase in ethanol content prolonged ID significantly at low temperatures, but had minor effects on laminar flame speeds. A comprehensive investigation on how laminar flame speed is influenced by ethanol addition into gasoline was carried out by Dirrenberger et al. [74], with a detailed mechanism of 304 species. The study suggested that the effect of ethanol on laminar burning velocities was negligible for proportions up to $15 \%$ by volume. Cai and Pitsch [32] formulated a reduced model with TRF and ethanol through automatic calibration by performing optimization of reaction rate rules [104] which provided computational advantage as kinetically similar reactions were grouped together. The inclusion of substituted aromatic species allowed correct prediction of PAH which led to soot formation eventually. Unlike most quaternary fuel models which retained the three important fuel species of TRF, the detailed mechanism developed by Yahyaoui et al. [68] comprised iso-octane, toluene, 1-hexene and ethyl tert-butyl ether with 234 species participating in 1860 reactions. Experimental ID in ST and species concentration profiles were well reproduced by the kinetic mechanism.

Apart from the three fuel components in TRF, five-component reaction mechanisms include additional representative species to model any other two hydrocarbon classes among cycloalkane, olefin and oxygenate. One such detailed model was formulated by Naik et al. [77] which included two additional fuel constituents of MCH and 1-pentene and consisted of 1328 species and 5835 reactions. Cross reactions between PRF and toluene and MCH mainly involved the hydrogen abstraction reactions. Besides, the abstraction reactions by allylic radicals from olefins were included due to their high production during the oxidation of alkanes at temperatures below $1000 \mathrm{~K}$. Due to the large size of mechanism, a single-zone and adiabatic engine model was used to compute HCCI combustion phasing which showed similar trends as in the experiments [77]. In Bunting et al.'s work [79], the quinary fuel surrogate model utilized 1hexene in place of 1-pentene for single-zone and multi-zone engine modeling of HCCI combustion. To address the widespread usage of gasoline-ethanol blends, kinetic mechanisms composed of TRF, DIB and ethanol as fuel components are constructed. Andrae [78] presented a corresponding detailed model with 1121 species among 4961 reactions including cross reactions between PRF and toluene and DIB. Besides reproducing ID times from ST for surrogate fuels, the mechanism was capable to predict both synergistic and antagonistic effects on MON qualitatively due to non-linear blending behavior among the fuels. Based on the previous TRF model [54], Andrae and Head [80] added mechanisms of ethanol and DIB to form a semidetailed model with 142 species and 672 reactions. The mechanism was validated against experimental information from ST, laminar flame speeds and HCCI engines. Their study pointed out that toluene, DIB and ethanol helped in advancing ignition at high intake temperature under HCCI conditions because fuels with the least negative temperature coefficient behavior exhibit lesser resistance to auto-ignition when the intake temperature is higher. The detailed model proposed by Cancino et al. [81] which possessed 1130 species and 5242 reactions was aimed to model ID times measured in ST experiments conducted at 720-1220 K and 10 and 30 bar for the quinary mixture of gasoline-ethanol blends. Despite underestimation of ID by about $15 \%$ at the pressure of 30 bar, the model showed overall better agreement than the prediction by Andrae's model [78]. A reduced five-component kinetic model with 89 species and 355 reactions was 
developed by Zhong and Zheng [82]. Validations against ID, flame speeds, species profiles and pressure curves under HCCI configurations were performed for neat hydrocarbons, surrogate mixtures and real gasoline. Apart from TRF and ethanol, Ranzi et al. [63] included mechanisms of methanol and 1-butanol to represent the family of alcohols in bio-gasoline. The resulting reduced model had 171 species and 3754 reactions.

Several complex and detailed reaction models for gasoline combustion are available whereby the mechanisms of up to seven or eight fuel constituents are incorporated. Hashimoto et al. [87] built a combustion reaction model which covered paraffins, olefins, naphthenes, alcohols, ethers and aromatics with 803 species among 3222 reactions. The mechanisms accounting for paraffins, olefins, naphthenes and alcohols were generated automatically before merging them with others. The model was however used solely to simulate the combustion in a RCM for different surrogate mixtures and comparisons were made in terms of hot ignition period. In order to emulate the targeted properties of typical gasoline fuels, a detailed mechanism with 1477 species and 6827 reactions was combined by Puduppakkam et al. [83], based on the optimized seven-component fuel blend obtained from a software program, the Surrogate Blend Optimizer. Correct trends of combustion phasing and emissions of $\mathrm{NO}_{\mathrm{x}}$ and unburned hydrocarbons (UHC) from a $\mathrm{HCCI}$ engine were replicated. In another study on $\mathrm{NO}_{x}$ sensitization in fuel oxidation [105], a detailed model [84] consisting of 1833 species and 8764 reactions was applied under JSR and HCCI conditions. Eight components, namely TRF, $\mathrm{MCH}, 1$-pentene, iso-hexane, n-pentane and npropyl benzene as well as mechanisms of NOx and PAH formation were encompassed. Reduction of the detailed mechanism [84] performed by Naik et al. [85] through automated strategies resulted in a 438-species mechanism for engine modeling. On the other hand, the multi-component chemistry (MultiChem) mechanism with 113 species and 487 reactions proposed by $\mathrm{Ra}$ and Reitz [86] was tailored to model oxidation of automotive fuels like diesel and gasoline in internal combustion engines. Relevant to gasoline, auto-ignition in ST and pressure profiles under HCCI conditions were well predicted. Nonetheless, validation of the chemistry at low-to-intermediate temperatures was required to improve the model performance. The accurate predictions by very detailed and complex fuel models come at the expense of relatively large mechanism size with more than 1000 species, thus rendering their applications in multi-dimensional numerical simulations.

It is evident that many reaction mechanisms for gasoline fuels have been developed over the years owing to the continuing development of kinetic studies in hydrocarbon classes and advancement in mechanism generation as well as reduction techniques. The models are usually formulated targeting to match important validation parameters under a particular range of engine operating conditions. Moreover, more species and reactions are consistently added while their reaction rates are updated from time to time to enhance the overall model prediction. Generally, most, if not all, of the kinetic models are validated under HCCI operating conditions for engine applications, as shown in Table 3. This, however, does not guarantee good performance for GDI engine applications due to the fundamental differences in the combustion mode, starting with the inclusion of spark ignition. The incorporation of chemical models in simulating combustion in GDI engines is rather limited as discussed in the next section. In fact, mostly simplified monoand bi-component of iso-octane and PRF, respectively, have been utilized in the associated numerical CFD studies. To address the multi-component nature of real gasoline fuels, complex reaction mechanisms need to be developed and adapted for combustion conditions within GDI 
engine setups. At the same time, care should be taken to avoid intractable computational time caused by the detailed chemical fuel models.

\section{CFD Modeling of Engine Phenomena of GDI Engines}

The combustion processes in internal combustion engines essentially involve complex gas dynamics and flows, heat transfer among different components and significant turbulencechemistry interactions [106]. Within a single engine cycle, combustion regimes can change between premixed turbulent flame propagation, mixing-controlled non-premixed combustion and chemical-kinetics-controlled burning [25]. Therefore, the role of combustion science, particularly in advanced development of gasoline engines is prevalent along with the concurrent applications of modern optical diagnostics, multi-dimensional CFD modeling and conventional combustion diagnostic tools [107] in understanding the fundamental in-cylinder processes. Among all, numerical simulations serve to represent such physical and chemical processes partly or completely with their tailored mathematical models to generate computational outcome providing valuable insights for engine performance optimization [106]. Within GDI engine configurations, the flows induced during spray, in-cylinder mixing, ignition and combustion are compressible and transient [108]. Generally, the associated key physical processes cover intake air flow, fuel injection, spray and vaporization, mixture preparation and formation, spark ignition and early flame formation, turbulent flame propagation, exhaust flow with engine-out emissions [107]. These various stages have varying degrees of influence on the overall engine performance in which different parameters from each stage affect the output independently or collectively. Successful simulations of the in-cylinder processes then rely on the modelers' judgment and knowledge in appropriate selection of CFD models and schemes in order to draw meaningful comparisons with on-going experimental measurements in the field.

The emphasis of current modeling works in GDI engine development is placed on understanding spray phenomena, mixture preparation and combustion processes. While spray and mixture formation aspects can be examined separately in detail to optimize injector design and position as well as combustion chamber geometry, combustion modeling often depends on the accuracy of numerical studies for the former two preceding processes. The present work briefly summarizes the most relevant information regarding in-depth studies of spray and mixture formation; the main focus is instead directed towards the growing trend of combustion modeling within GDI engine configurations. Three-dimensional CFD combustion simulations performed under various GDI engine setups which have been validated against experimental and optical measurements are tabulated, to the authors' best knowledge, in Table 4 along with the corresponding engine parameters used for comparisons. Modeling studies incorporating investigation of soot processes for GDI engines are not included here but treated subsequently. 
Table 4 Multi-dimensional CFD combustion modeling of GDI engines with optical and/or experimental validations.

\begin{tabular}{|c|c|c|c|c|c|}
\hline Year & Author(s) & Code & CFD sub-models & Parameter comparison $^{\mathrm{a}}$ & $\mathrm{H} / \mathrm{S}$ \\
\hline 1996 & Gill et al. [109] & KIVA-II & $\mathrm{k}-\epsilon$ turbulence, spray, flamelet & In-cylinder pressure, species concentration & $\overline{\mathrm{S}}$ \\
\hline 1998 & Kech et al. [110] & KIVA-3V & Hollow-cone fuel spray, flame area evolution & In-cylinder pressure & $\mathrm{S}$ \\
\hline 1998 & $\begin{array}{l}\text { Duclos and Zolver } \\
{[111]}\end{array}$ & KMB & $\begin{array}{l}\text { k- } \epsilon \text { turbulence, Kays and Crawford's heat transfer, hollow-cone fuel spray, Naber } \\
\text { and Reitz's wall impingement, coherent flame model (CFM), Zeldovich et al.'s NO }\end{array}$ & In-cylinder pressure, $\mathrm{NO}$ and $\mathrm{CO}$ emissions & $\mathrm{H}, \mathrm{S}$ \\
\hline 1998 & $\begin{array}{l}\text { Tatschl and Riediger } \\
{[112]}\end{array}$ & FIRE & $\begin{array}{l}\text { k- } \epsilon \text { turbulence, transported multi-scalar probability density function (PDF) } \\
\text { combustion }\end{array}$ & $\begin{array}{l}\text { Flame size probability distribution, flame front } \\
\text { speed, heat release rate }\end{array}$ & $\mathrm{H}, \mathrm{S}$ \\
\hline 1999 & Henriot et al. [113] & KMB & WAVE-FIPA, Naber and Reitz's wall impingement, extended CFM (ECFM) & In-cylinder pressure, $\mathrm{NO}$ and $\mathrm{UHC}$ emissions & $\mathrm{H}, \mathrm{S}$ \\
\hline 1999 & Duclos et al. [114] & KMB & Spray, ECFM, Zeldovich et al.'s NO & In-cylinder pressure, $\mathrm{NO}$ emission & $\mathrm{H}, \mathrm{S}$ \\
\hline 1999 & Fan et al. [115] & KIVA-3V & $\begin{array}{l}\text { Hollow-cone fuel spray, Taylor analogy breakup (TAB), Naber and Reitz's wall } \\
\text { impingement, characteristic-time combustion (CTC), Zeldovich et al.'s NO, spark } \\
\text { plug protrusion, discrete particle ignition kernel (DPIK), RNG k-€ turbulence }\end{array}$ & In-cylinder pressure & $\mathrm{H}, \mathrm{S}$ \\
\hline 2000 & Georjon et al. [116] & KIVA-II & $\begin{array}{l}\text { k- } \epsilon \text { turbulence, WAVE-FIPA, Naber and Reitz's wall impingement, ECFM, } \\
\text { Zeldovich et al.'s NO }\end{array}$ & $\begin{array}{l}\text { Spray shape, spray penetration, flame propagation, } \\
\text { evaporated mass fraction, in-cylinder pressure, NO } \\
\text { emission }\end{array}$ & $\mathrm{S}$ \\
\hline 2000 & Tatschl et al. [117] & FIRE & Hollow-cone spray, transported multi-scalar PDF combustion & $\begin{array}{l}\text { Spray shape, penetration length, fuel distribution, } \\
\text { reaction products distribution, fuel mass } \\
\text { concentration }\end{array}$ & $\mathrm{S}$ \\
\hline 2001 & Hélie et al. [118] & KMB & $\begin{array}{l}\text { k- } \epsilon \text { turbulence, Angelberger et al.'s heat transfer, hollow-cone fuel spray, ECFM, } \\
\text { eddy-dissipation model (EDM), Zeldovich et al.'s NO }\end{array}$ & In-cylinder pressure & $\mathrm{S}$ \\
\hline 2001 & Nomura et al. [119] & STAR-CD & k- $\epsilon$ turbulence, DDM, Naber and Reitz's wall impingement, CFM & Spray shape, fuel distribution, equivalence ratio field & $\mathrm{S}$ \\
\hline 2002 & $\begin{array}{l}\text { Wallesten et al. } \\
{[120]}\end{array}$ & FIRE & $\begin{array}{l}\text { Lagrangian approach, Naber and Reitz's wall impingement, flame speed closure } \\
\text { (FSC) }\end{array}$ & $\begin{array}{l}\text { Flow field, equivalence ratio field, in-cylinder } \\
\text { pressure, UHC emission }\end{array}$ & $\mathrm{H}, \mathrm{S}$ \\
\hline 2003 & Castagné et al. [121] & KMB & $\begin{array}{l}\text { k- } \epsilon \text { turbulence, Kays and Crawford's heat transfer, hollow-cone fuel spray, Naber } \\
\text { and Reitz's wall impingement, combustion }\end{array}$ & $\begin{array}{l}\text { Spray shape, fuel concentration at spark plug, in- } \\
\text { cylinder pressure, indicated mean effective pressure } \\
\text { (IMEP) }\end{array}$ & $\mathrm{S}$ \\
\hline 2003 & Colin et al. [122] & KMB & ECFM, arc and kernel tracking ignition model (AKTIM), knock, scalar fluctuation & In-cylinder pressure, equivalence ratio field & $\mathrm{H}, \mathrm{S}$ \\
\hline 2003 & $\begin{array}{l}\text { Wakisaka and } \\
\text { Esumi [123] }\end{array}$ & GTT & Hollow-cone spray, CTC & $\begin{array}{l}\text { Spray shape, Sauter mean diameter (SMD), fuel mass } \\
\text { concentration, in-cylinder pressure }\end{array}$ & $\mathrm{S}$ \\
\hline 2003 & Tan et al. [124] & KIVA-3V & $\begin{array}{l}\text { Linearized instability sheet atomization (LISA), RNG k- } \epsilon \text { turbulence, Han and } \\
\text { Reitz's heat transfer, Naber and Reitz's wall impingement, Zeldovich et al.'s NO, } \\
\text { DPIK, G-equation, CTC }\end{array}$ & In-cylinder pressure, $\mathrm{NO}$ emission & $\mathrm{S}$ \\
\hline 2004 & $\begin{array}{l}\text { Vanzieleghem et al. } \\
{[125]}\end{array}$ & KIVA-3V & LISA, TAB, Grover et al.'s wall impingement, ECFM & $\begin{array}{l}\text { Spray vaporization rate, in-cylinder pressure, } \\
\text { equivalence ratio field }\end{array}$ & $\mathrm{H}, \mathrm{S}$ \\
\hline 2005 & Drake et al. [126] & GMTEC & $\begin{array}{l}\text { k- } \epsilon \text { turbulence, Stanton and Rutland's spray-wall interaction, modified Bray-Moss- } \\
\text { Libby (BML), EDM }\end{array}$ & $\begin{array}{l}\text { Spray shape, combustion location and progression, } \\
\text { in-cylinder pressure, mass burn rate }\end{array}$ & $\mathrm{S}$ \\
\hline 2005 & Gao et al. [127] & KIVA-3V & Liquid sheet atomization, TAB, O'Rourke and Amsden's wall impingement, CTC & In-cylinder pressure & $\mathrm{S}$ \\
\hline 2005 & $\begin{array}{l}\text { Olmo and Thornton } \\
{[128]}\end{array}$ & STAR-CD & $\begin{array}{l}\text { Lagrangian approach, Reitz-Diwakar's breakup, El Wakil's evaporation, Bai's wall } \\
\text { impingement, ECFM, EBU, Zeldovich et al.'s NO }\end{array}$ & $\begin{array}{l}\text { Spray shape, SMD, mean diameter, droplet size } \\
\text { distribution, in-cylinder pressure, mass burn rate }\end{array}$ & $\mathrm{H}, \mathrm{S}$ \\
\hline 2006 & Liu et al. [129] & ICFD-CN & $\begin{array}{l}\text { Kelvin-Helmholtz and Rayleigh Taylor (KH-RT), TAB, Lefebvre fuel vaporization, } \\
\text { O'rourke and Bracco's droplet impingement and coalescence, Stanton's wall } \\
\text { impingement, DPIK, single-step combustion, Zeldovich et al.'s NO }\end{array}$ & In-cylinder pressure, $\mathrm{NO}$ emission & $\mathrm{S}$ \\
\hline 2006 & Rotondi [130] & NCF-3D & $\begin{array}{l}\text { k- } \epsilon \text { turbulence, Nagaoka and Kawamura's primary atomization, WAVE, TAB, DDB, } \\
\text { CTC, spark plug }\end{array}$ & Penetration length, spray shape, in-cylinder pressure & $\mathrm{H}, \mathrm{S}$ \\
\hline 2006 & Bohbot et al. [131] & IFP-C3D & WAVE-FIPA, 3-zone ECFM, RNG k- $\epsilon$ turbulence & $\begin{array}{l}\begin{array}{l}\text { Intake pressure, in-cylinder pressure, species } \\
\text { concentration }\end{array} \\
\end{array}$ & $\mathrm{H}$ \\
\hline
\end{tabular}




\begin{tabular}{|c|c|c|c|c|c|}
\hline 2006 & $\begin{array}{lll}\text { Liang } & \text { and } & \text { Reitz } \\
{[132]}\end{array}$ & KIVA-3V & DPIK, G-equation & In-cylinder pressure, $\mathrm{NO}$ emission & $\mathrm{S}$ \\
\hline 2008 & Kim et al. [133] & STAR-CD & Reitz-Diwakar's breakup, modified eddy-breakup model (EBM), k- $\epsilon$ turbulence & Spray shape, in-cylinder pressure & $\mathrm{S}$ \\
\hline 2009 & $\begin{array}{lll}\text { Yang } & \text { and } & \text { Reitz } \\
{[134]}\end{array}$ & KIVA-3V & CMC, G-equation & In-cylinder pressure, heat release rate & $\mathrm{S}$ \\
\hline 2009 & Dahms et al. [135] & ACFluX & $\begin{array}{l}\text { k- } \epsilon \text { turbulence, spray, spark channel ignition monitoring model (SparkCIMM), G- } \\
\text { equation }\end{array}$ & $\begin{array}{l}\text { Spark and combustion luminosity, flame probability } \\
\text { contours }\end{array}$ & $\mathrm{S}$ \\
\hline 2010 & Bai et al. [136] & FIRE & WAVE, Naber and Reitz's wall impingement, PDF combustion & Spray shape, penetration length, in-cylinder pressure & $\mathrm{H}, \mathrm{S}$ \\
\hline 2012 & Dahms et al. [137] & ACFluX & $\begin{array}{l}\text { DDM, Lagrangian approach, k- } \epsilon \text { turbulence, CMC, Grover et al.'s wall } \\
\text { impingement, SparkCIMM, G-equation }\end{array}$ & $\begin{array}{l}\text { Flame probability contours, in-cylinder pressure, heat } \\
\text { release rate, characteristic burn points, combustion } \\
\text { efficiency }\end{array}$ & $\mathrm{S}$ \\
\hline 2012 & Yang et al. [138] & CONVERGE & $\begin{array}{l}\text { RNG k- } \epsilon \text { turbulence, Lagrangian approach, O'Rourke and Amsden's wall } \\
\text { impingement, Arrhenius combustion, spark-energy deposition }\end{array}$ & Heat release rate & $\mathrm{H}$ \\
\hline 2013 & Givler et al. [139] & CONVERGE & RNG k-€ turbulence, KH-RT, multi-zone & In-cylinder pressure & $\mathrm{H}, \mathrm{S}$ \\
\hline 2014 & Bonatesta et al. [38] & STAR-CD & $\begin{array}{l}\text { Lagrangian approach, Reitz-Diwakar's breakup, RNG k- } \epsilon \text { turbulence, Bai-ONERA } \\
\text { wall impingement, 3-zone ECFM }\end{array}$ & $\begin{array}{l}\text { Spray shape, penetration length, SMD, in-cylinder } \\
\text { pressure, rate of pressure variation }\end{array}$ & $\mathrm{H}$ \\
\hline 2014 & Costa et al. [140] & FIRE & $\begin{array}{l}\text { DDM, Mundo-Sommerfeld's wall impingement, 3-zone ECFM, Zeldovich et al.'s } \\
\text { NO }\end{array}$ & $\begin{array}{l}\text { Spray shape, in-cylinder pressure, flame surface } \\
\text { density, flame duration, NO and UHC emissions }\end{array}$ & $\mathrm{H}$ \\
\hline 2015 & Kim et al. [141] & KIVA-3V & $\begin{array}{l}\text { KH-RT, O'Rourke and Amsden's wall impingement, Lagrangian approach, RNG k- } \\
\epsilon \text { turbulence, DPIK, G-equation }\end{array}$ & $\begin{array}{l}\text { Penetration length, spray shape, in-cylinder pressure, } \\
\text { heat release rate, flame speed }\end{array}$ & $\mathrm{H}$ \\
\hline
\end{tabular}

${ }^{a}$ Validation by comparing engine parameters against optical and/or experimental measurements obtained from GDI test bed facilities. ${ }^{b} \mathrm{H} / \mathrm{S}$ represents homogeneous- or stratified-charge combustion modes 
In simulating IC engine applications numerically, one of the most prominent and significant aspects is the accuracy of turbulence modeling. Turbulent combustion modeling for reciprocating-piston IC engines was reviewed by Haworth [25] for basic combustion systems. Overall, three distinct approaches in solving the chemically reacting turbulent flow fields are Reynolds-averaged Navier-Stokes (RANS) equations, large eddy simulation (LES) and direct numerical simulation (DNS). The descriptions, developments and comparisons of these approaches relevant to computational combustion have been discussed elsewhere [25], [107], [142], [143]. To sum up, RANS modeling which solves for ensemble-averaged mean quantities remains as the core in CFD simulations nowadays. Among all RANS-based models, standard k- $\epsilon$ turbulence model is among the most commonly and widely utilized in engine studies including GDI technology. It is a two-equation model whose dependent variables are turbulent energy, $\mathrm{k}$ and energy dissipation rate, $\epsilon$ [144]. Nonetheless, the applicability of model is limited to cases with sufficiently high Reynolds numbers or wellestablished wall functions. Difficulties arise at low and transitional Reynolds numbers, particularly in modeling near-wall turbulence behavior [145]. Consequently, several other turbulent models are formulated with modifications including $\mathrm{k}-\epsilon-\mathrm{v}^{2}$ model for separated flows [146], re-normalization group (RNG) k-€ model for small-scale flows [147] and Reynolds stresses model to compute Reynolds stresses based on their transport equations [148]. Meanwhile, through spatial filtering of the governing equations, LES works by capturing the large-scale dynamics which can be resolved on the computational mesh and modeling only the unresolved small-scale processes. This is because the large-scale motion contains most of the kinetic energy and regulates the dynamics of turbulent flow field [149]. On the other hand, DNS solves the non-averaged, unfiltered instantaneous governing equations through computational meshes and numerical methods resolvable at all relevant scales. However, the main drawback is its limitations to low Reynolds numbers and simple geometric configurations [150].

In relation to IC engines, the superiority of LES over RANS approach remains arguable in terms of applicability and accuracy. While LES is more computationally expensive than RANS [149], it better characterizes the in-cylinder flows due to the presence of large-scale unsteadiness, cyclic variations and low-to-moderate Reynolds number [107]. In contrast, the use of ensemble-averaged engine data in RANS-based results has been extensive and successful over the years in CFD modeling at efficient and affordable computational efforts. Moreover, it is necessary to perform LES through multiple engine cycles with appropriate conditional averaging in order to draw meaningful comparisons with experimental engine data [25]. Therefore, it is speculated that RANS will continue to be the leading mainstream CFD approach in engine modeling development [107]. At the same time, studies are increasingly directed at tapping the potential of LES in realistic engine applications. On a side note, DNS is impractical for complex engine phenomena modeling and even unlikely desirable for the foreseeable future [25]. Nonetheless, DNS can be applied to complement the modeling in developing and calibrating models for RANS and LES [107]. Current modeling exercise is largely constrained by the random nature of turbulence. Turbulence contributes to the cycle-to-cycle variations observed in SI engines as evidenced in the work by Johansson [151] in which $50 \%$ of the flame growth rate fluctuations were attributed to cyclic variations in turbulence when the engine was run without fluctuations in fuel or residual gas.

\subsection{Spray, Mixture Formation and Combustion Modeling}

In GDI engines, the direct injection of fuel into the combustion chamber causes inherently shorter time available for evaporation and mixing. It then requires the need of higher injection pressures to achieve a well-atomized spray with good penetration. The study of spray modeling is therefore, essential to formulate proper spray and injection strategies and 
optimize injector designs. Conceptually, spray combustion can be divided into liquid penetration, breakup, formation of droplets, transport of droplets during evaporation, collision, scattering, recombination and slow down, and gas-phase reactions [142]. Due to a wide range of size and time scales, the study of spray involves complex interactions with the surrounding gas which can be characterized by a two-phase flow [108]. Consequently, various sub-models are formulated to describe the sub-grid scale spray-related processes which include atomization, drop breakup and deformation, drop collision and coalescence, drop vaporization and impingement between spray and wall. Based on current capabilities in CFD, spray modeling is relatively poorly understood which is partly caused by difficulty in obtaining optical measurements in the near-nozzle region [107]. Fortunately, the area of study in spray modeling has been receiving increasing attention. Early spray models simulated the transport of droplets with the assumption of an initial distribution of size, velocity and even composition of droplets. The effects of other droplet dynamics such as collisions and coalescence were later included [142]. Currently, spray models are tuned and tailored to reproduce quantities such as penetration lengths, radial profiles of droplets size and velocity downstream of the nozzle, which are measured experimentally [107].

Within a spray regime, dense spray consists of the liquid core and the dispersed flow region. Across the dispersed flow region, a multiphase mixing layer is formed, followed by a jet evolving into a dilute spray flow [152]. Three major approaches to deal with the multiphase flow are identified [108] as volume of fluid (VOF) method [153], Eulerian method [154] and discrete droplet model (DDM) in a Lagrangian framework [155]. The application of DDM dominates the current spray modeling works because of its simplicity and steadiness [108]. Of particular importance, the atomization breakup of spray can be divided into primary and secondary breakups which are often modelled separately in computational spray studies. Primary breakup refers to the formation of ligaments and irregular liquid elements along the liquid core surface [152], thus initiating atomization, controlling the length of liquid core and establishing initial conditions for the dispersed flow region [156]. While the exact mechanisms of jet atomization remain ambiguous, several explanatory theories are summarized [157] to be aerodynamic shear stresses [158], inner liquid turbulence [152], velocity profile relaxation [159], bulk liquid oscillation [160] and cavitation-induced disturbances [160]. One or more of these theories then provide the underlying principles for atomization models. In secondary breakup, liquid droplets detached from the liquid core undergo further disintegration into even smaller fragments. Depending on Weber number and time of deformation, the secondary breakup modes can be categorized into bag breakup, stripping breakup and catastrophic breakup [161]. Under the bag breakup mode, the droplets are stretched to form a flat disk which transforms into a thin membrane. The membranes burst into fine droplets eventually. In the stripping breakup, the membranes collapse at their edges to form small droplets. On the other hand, droplets are elongated and broken into small fragments through catastrophic breakup as a result of the extremely high relative velocity between gas and liquid phases [162].

Other physical processes occurring on the droplets formed include drag and deformation, collision, vaporization and wall impingement which are modelled at varying levels in spray simulations. For example, drop-to-drop collisions were neglected in several spray modeling studies of GDI engines [37], [38]. This is because droplet collision and coalescence are expected to be trivial in such engine simulations as mixing and vaporization processes occur far from the nozzle where the spray is well-dispersed [37]. Aerodynamic drag force induced from the relative velocity of gas-liquid interface causes deceleration and distortion of droplets [163]. Droplet collision and coalescence are particularly dominant in the dense spray regime. Collisions result in five distinct regimes, namely slow coalescence, bouncing, coalescence, 
reflexive separation and stretching separation which differ according to Weber number and impact parameter [164]. Drop vaporization links the spray breakup stage to the mixture preparation mode which determines the combustion characteristics subsequently. The basic droplet vaporization model, $\mathrm{d}^{2}$-law model was proposed by Godsave [165] and Spalding [166]. The model held that the square of droplet diameter decreases linearly with time for a pure fuel droplet under stagnant conditions. Moreover, vaporization models for multicomponent fuel sprays are also developed due to the nature of most practical fuels which can be grouped into continuous multi-component (CMC) and discrete multi-component (DMC) models. The CMC approach utilizes a continuous distribution function of suitable parameters such as molecular weight to represent the fuel composition. The DMC method instead involves tracking individual fuel components which have different properties during the vaporization process [167]. In terms of spray-wall impingements, common impingement regimes caused by interactions between drops and surfaces are stick, rebound, spread and splash [168]. Impingement models formulated describe transition regimes which cover two different regimes as evidenced from experimental studies [169].

For spray modeling, simple spray models such as the Reitz-Diwakar model are commonly applied in CFD simulations of GDI engines [38], [128], [133] owing to their simplicity with reasonable model predictions. The particular model works on the limiting assumption that all the injected droplets have the same initial diameter as the size of nozzle exit. The whole droplet disintegration is demanded to the subsequent secondary breakup [170], [171]. Nonetheless, more complex spray models are utilized to yield a more accurate description of the entire spray phenomenon. One such model is the KH-RT model which has been increasingly adapted in GDI engine simulations [129], [139], [141]. Huang and Lipatnikov [172] compared liquid penetration and SMD of gasoline and ethanol sprays predicted by various spray models which were implemented in an open source code called OpenFOAM. They concluded that the KH-RT model displayed the best agreement particularly at high pressure conditions. Within the framework, the droplet breakup is caused by the growth of competing instabilities of $\mathrm{KH}$ and $\mathrm{RT}$ [172]. The breakup due to KH instability is induced by relative velocity at the interface whereas RT instability is caused by the influence of liquid acceleration within the gas flow field [173]. Notably, KH and RT models are intrinsically inter-related, thus enhancing numerical capture capability of primary and secondary breakup processes.

The quality of fuel-air mixing and mixture preparation directly determine the resulting combustion characteristics of fuels within the combustion chamber. Generically, based on the level of mixture homogeneity of fuel and air at the time of ignition, the combustion is distinguished between theoretically homogeneous charge or stratified charge which are the two main variants of combustion mode in GDI engines [25] as illustrated schematically in Figure 2. The former involves injection of fuel early during the intake stroke to allow spatial homogeneity of the in-cylinder mixture [107]. The combustion is then characterized by a premixed turbulent flame propagation [25]. Conversely, the stratified system applies late fuel injection (normally during the compression stroke) to form a layered charge featuring a fuelricher zone in the vicinity of the spark plug, while the charge remains globally lean [25]. The two-stage combustion mode is primarily initiated through premixed turbulent flame propagation near the spark plug, followed by a secondary diffusion-controlled combustion as unoxidized or partially oxidized fuel fragments in locally rich zones react with leftover oxygen from fuel-lean regions [107]. Over the years, both combustion types of homogeneous and stratified charge are examined thoroughly under GDI engine configurations as outlined in Table 4. While some knowledge regarding GDI engines operating in a homogeneous mode can be extracted from studies of conventional gasoline engines with PFI due to similarities in 
the combustion processes, stratified combustion presents further complications as a result of its two-stage behavior coupled with the effects of turbulent fluctuations. While a formal distinction between homogeneous and stratified operation remains essential, it is noted that, due to the inherent short time for fuel vaporization and mixing, proper combustion chamber homogeneity is extremely difficult to achieve in a GDI engine. The permanence of substoichiometric regions at the time of ignition leads to local stratification, which is addressed to as one of the most important triggers for soot formation [17], [20]. Besides soot emissions, Bohbot et al. [131] associated the inaccurate prediction of UHC and NO emissions from a 4cylinder turbocharged GDI engine to the assumption of homogenous mixture used in the three-dimensional (3D) calculations.
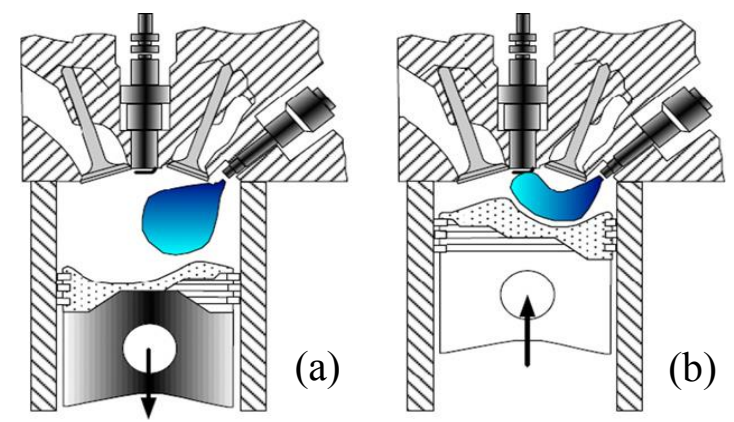

Figure 2 (a) Homogeneous and (b) stratified charge formation in a GDI engine [6].

In order to reap the benefits in fuel economy offered by stratified charge combustion, insights about the process in GDI engines need to be obtained through simultaneous applications of advanced numerical, experimental and optical tools. In the two-stage combustion, higher amount of heat release occurs at the first premixed combustion as compared to the subsequent diffusion-controlled combustion [174]. Furthermore, premixed burning mode is inherently more complex than non-premixed one due to the stronger coupling between chemistry and turbulence, thus causing less advanced predictive capabilities in the contemporary numerical models [143]. Therefore, significant modifications and improvements are performed on the current turbulent combustion models to be adopted for accurate combustion modeling of GDI engines. Several relevant combustion models which are widely utilized include EBU model, CTC model, BML model, CFM and its variants, G-equation model and FSC model. Brief descriptions of the models are provided in Table 5 where detailed information can be found in the references cited.

Table 5 Relevant combustion models applied within GDI engine configurations.

\begin{tabular}{llll}
\hline Combustion model & Brief description & Reference \\
\hline EBU & $\begin{array}{l}\text { Reaction rates are controlled by the rate of entrainment caused by turbulent } \\
\text { mixing. }\end{array}$ & {$[175]$} \\
\hline CTC & $\begin{array}{l}\text { Species conversion time is a combination of both turbulent-mixing time and } \\
\text { chemical-kinetics time. }\end{array}$ & {$[176]$} \\
\hline BML & $\begin{array}{l}\text { Thermochemical state of the mixture is expressed as a single scalar } \\
\text { combustion progress variable, c based on the flamelet concept. }\end{array}$ & {$[177]$} \\
\hline CFM & $\begin{array}{l}\text { Mean chemical reaction rate is the product of reaction rate per unit area of } \\
\text { flamelets and flame surface density. }\end{array}$ & {$[178]$} \\
\hline G-equation & $\begin{array}{l}\text { Flame surface is described by a smooth function, G with the assumption of } \\
\text { negligible thickness in the level set approach. }\end{array}$ & {$[179]$} \\
\hline FSC & $\begin{array}{l}\text { Combustion is modelled as a single transport equation for the reaction } \\
\text { progress variable, c. }\end{array}$ & {$[180]$} \\
\hline
\end{tabular}


Early combustion modeling in GDI engines was carried out by Gill et al. [109] who first modified the classical flamelet model by treating the turbulent diffusion flame during stratified combustion as an ensemble of laminar flamelets. Premixed burning mode was not taken into consideration. More importantly, the flamelet model coupled with a detailed reaction mechanism showed closer agreement to experimentally-measured pressures and species mass concentrations as compared to the simplified-chemistry model. Chemical kinetics and turbulence-chemistry interactions provided the direction for following computational combustion studies in IC engines. Kech et al. [110] modeled the partially premixed combustion through the flame area evolution model which was able to replicate a triple flame configuration observed in stratified engines [181]. The abrupt rise in cylinder pressures predicted after ignition was attributed to the higher spray vaporization simulated. Both homogeneous and stratified operating conditions of a real GDI engine were simulated by Duclos and Zolver [111]. The combustion process was modeled with CFM whereby average cylinder pressures and NO emission were properly predicted. Prediction of $\mathrm{CO}$, on the other hand, was less satisfactory due to uncertainties in fuel stratification and simplicity of kinetic mechanism used. In a successive study by Duclos et al. [114], an extended version of CFM, ECFM was applied which relied on the thermo-chemical properties of unburnt and burnt gases. Similarly, good agreement in pressure traces and NO concentration was achieved. ECFM was also employed by Henriot et al. [113] to study combustion characteristics in a small bore GDI engine and Georjon et al. [116] to compute and validate numerical results on mixture preparation and combustion against experimental data from a research engine with optical accesses.

The approach to simulate turbulent reacting flows in stratified-charge combustion by Tatschl and Riediger [112] involved solving a PDF transport equation for scalars including mixture fraction, reaction progress variable and enthalpy. Good agreement was observed between calculated heat release rate and experimental values extracted from in-cylinder pressure measurements. In a later study, Tatschl et al. [117] integrated advanced meshing tools into the similar combustion modeling method at part load operating conditions. Engine parameters related to spray combustion were compared with experimental measurements. The modeling work of Fan et al. [115] focused on investigating effects of injection angle and tumble ratio for a GDI engine operating at part load. The combustion was described by the CTC model [176] which considered both turbulent-mixing time and kinetics time. The CFD models were first validated in a propane-fueled SI engine where in-cylinder pressures were correctly reproduced across different ignition timings. It was shown that injection orientation, piston deflection and gas tumble determined proper preparation of fuel stratification in the combustion chamber. The application of CTC model to simulate stratified charge combustion in GDI engines was also observed in the works by Wakisaka and Esumi [123], Gao et al. [127] and Rotondi [130]. Hélie et al. [118] applied ECFM in stratified-charge combustion modeling of GDI engines which considered the effect of local mixture fluctuations. The secondary mixing-controlled burning mode was governed by EDM. Calculated average cylinder pressures agreed well with measurements under different spark timing advances. Nomura et al. [119] performed 3D simulations of the combustion process in a GDI engine with fan-shaped spray. Besides fan spray shape, fuel distribution and equivalence ratio were validated. The results suggested the use of thin thickness fan spray coupled with compact cavity to reduce the amount of UHC.

Wallesten et al. [120] incorporated a reaction mechanism containing 100 species among 475 reactions into CFD combustion modeling of a GDI engine. The complex effect of chemistry was taken into account through calculation of laminar flame speed. In addition, the FSC model was implemented into the FIRE CFD code to simulate the combustion process. 
Computed in-cylinder pressures showed good correlation to the measured values under various engine speeds and loads. Castagné et al. [121] carried out 3D modeling studies which paralleled the experimental investigation on wall-guided and spray-guided GDI engines. Overall, cylinder pressure traces and IMEP across varying injection timing and spark advance were effectively reproduced. To improve the effect of large-scale stratification on combustion, Colin et al. [122] utilized the ECFM and adapted it for combustion of multi-component fuels. The combustion model involved defining a fictitious mean fuel locally to represent all the components of real gasoline fuel. Coupled with a knock model, the in-cylinder pressures were very well predicted. Also, average equivalence ratio and its fluctuation at the spark location were accurately modelled. Meanwhile, Tan et al. [124] used G-equation model to represent premixed flame propagation and CTC model to describe the subsequent diffusioncontrolled combustion. Based on the flamelet concept, G-equation allowed the calculations of chemical reaction and turbulent hydrodynamics to be decoupled. Reasonable agreement between measured and predicted in-cylinder pressures and NO concentrations was attained. The study was further extended by Liang and Reitz [132] who included chemical reaction mechanisms into G-equation combustion modeling. The fuel used in a two-stroke marine GDI engine was represented by a kinetic model of iso-octane with 21 species and 42 reactions. Calculated pressure curves and NO emission matched the experimental measurements for various spark timing settings.

Vanzieleghem et al. [125] studied full-cycle combustion modeling in a single-cylinder GDI engine with different swirl intensities at engine speeds of 600 and $2000 \mathrm{rev} / \mathrm{min}$. Furthermore, the CFM was extended to investigate the effect of EGR on flame propagation. The formulation enabled estimation of EGR percentage in each computational cell instead of homogeneous distribution assumption, thus allowing accurate flame speeds to be calculated. From the results, fairly small increase in EGR level caused large reduction in laminar flame speed. The two-stage stratified combustion behavior in a spray-guided GDI engine was modeled by Drake et al. [126] in which premixed combustion was described using modified BML flamelet model while EDM was applied to model diffusion-controlled burning. The CFD results highlighted that higher fuel burn rate was detected in the premixed combustion as compared to the diffusion mode. Similar observation was presented in Koch et al.'s work [182] whereby the first phase of heat release was dominated by premixed combustion. Liu et al. [129] developed a multi-dimensional model to characterize in-cylinder processes of GDI engines in order to optimize combustion chamber shape design. In the combustion model, burning rate was governed by chemical reaction rate initially, followed by turbulence dissipation rate. The model was first calibrated based on experimentally-measured pressures with a 5\% error tolerance. From the study, combustion chamber bowl offset of 0.5 to $1.0 \mathrm{~cm}$ was recommended to achieve the best balance between NO and UHC emissions. The work of Bohbot et al. [131] presented a direct temporal coupling of one-dimensional engine simulation tool and 3D combustion code and demonstrated its applicability for a 4-cylinder turbocharged GDI engine. Turbulent combustion modeling relied on the 3-zone ECFM with the assumption of homogeneous mixture formation. Such an assumption resulted in observable deviations in cylinder pressures and emissions predictions of $\mathrm{UHC}$ and $\mathrm{NO}_{\mathrm{x}}$.

Kim et al. [133] selected the modified EBM to simulate turbulent combustion in a sprayguided GDI engine whereby the influence of tumble flow on combustion and effects of injection timing and compression ratio on mixture formation were studied. Yang and Reitz [134] improved G-equation combustion modeling in GDI engines to incorporate the effects of multi-component fuels through the $\mathrm{CMC}$ approach. A reduced PRF mechanism consisting of 41 species and 130 reactions was also included to represent gasoline fuel. Under lean stratified-charge operating conditions, simulated cylinder pressures and heat release rates 
agreed well with experimental data at different manifold absolute pressures, injection and spark timings. Dahms et al. [135] integrated the SparkCIMM ignition model with the Gequation model in simulating combustion processes and validating the results against experimental findings in a spray-guided GDI engine in terms of flame probability contours. Particularly, the importance to include turbulence and mixture fraction fluctuations in modeling the development of the flame kernel by the ignition model was pinpointed. In a later study [137], a deeper investigation was done on a GDI engine operating at different engine speeds, loads, EGR, injection and spark timings. Excellent agreement was achieved between computed and measured pressure curves, heat release rates, characteristic burn points and combustion efficiencies. With validations of spray shape, penetration length and in-cylinder pressures, the modeling work by Bai et al. [136] showed that slower flame propagation and lower peak pressure were observed for stratified-charge combustion as compared to the homogenous combustion mode. Yang et al. [138] applied an Arrhenius combustion model which incorporated the effect of detailed chemistry. From the analysis, it was argued that combustion in spray-guided GDI engines occurred in a thickened flame regime. However, the effect of turbulent fluctuations was neglected by the combustion model. A PRF mechanism was employed by Givler et al. [139] to model combustion in both direct injection and PFI gasoline engines through the multi-zone approach. The importance of selecting a mechanism which was reduced under similar operating conditions to engine cases was specifically emphasized to ensure accurate predictions.

A recent theoretically-homogeneous and stoichiometric combustion modeling in a modern wall-guided GDI engine was performed by Bonatesta et al. [38] using the 3-zone ECFM model. The study sought to correlate in-cylinder processes to soot formation sources at different engine speeds. Spray modeling was first verified based on spray morphology and tip penetration to provide confidence for subsequent simulations of the engine cycle. For both mid and high engine speeds, computed average cylinder pressures and rates of pressure variation exhibited good agreement with the experimental data generally. Costa et al. [140] utilized simultaneous numerical and experimental techniques to investigate combustion in a wall-guided GDI engine under various injection strategies and ignition timings. Likewise, the spray sub-models were properly assessed. The combustion model, 3-zone ECFM was calibrated in terms of initial flame surface density and flame stretch factor to capture the pressure traces. Reasonable agreement between simulations and experiments was seen for flame propagation, flame durations and emissions of NO and UHC. The primary interest of Kim et al.'s work [141] was to examine the feasibility of a double injection strategy in GDI engines through 3D combustion modeling using G-equation model. It was shown that a first injection mid-way through the intake stroke, followed by an early second injection in the compression stroke enabled improved turbulence intensity, while maintaining the in-cylinder mixture homogeneity globally. Nevertheless, higher emissions were anticipated with such injection strategy due to the presence of overly-rich local zone at the intake port side.

The numerical investigation of combustion processes in GDI engines has been expanding in recent years to deepen the present understanding, along with the developmental works in experimental and optical techniques. Two main variants of combustion mode are possible, depending on the required engine operating conditions. Homogeneous-charge combustion in GDI engines somehow resembles that of the conventional PFI engines which is characterized by premixed flame propagation. Many CFD models developed for SI engines are extended for the applications in GDI engines with, however, due limitations associated to local charge stratification. Moreover, modeling stratified burning mode is deemed more challenging due to the aforementioned two-stage combustion behavior. Recent computational studies on combustion within GDI engine configurations have incorporated reduced chemical kinetic 
mechanisms to better represent the chemistry of gasoline fuels in computing the laminar flame speeds. Nonetheless, the mechanisms applied are restricted to those of single component iso-octane [132], [138], [141] and binary blends of PRF [120], [134], [137]. Hence, complex reaction mechanisms with multiple fuel components should be merged with combustion modeling works in GDI engines while significant efforts need to be directed at improving the current predictive capability of combustion models across a wide range of operating conditions.

\subsection{Soot Processes and Mechanisms in GDI Engines}

Despite enhancement in fuel economy due to improved thermal efficiency, GDI engines produce relatively substantial PM emission as compared to the conventional PFI engines and diesel engines mounted with DPFs in certain cases [7], [183], even exceeding $10 \mathrm{mg} / \mathrm{km}$ for some of the first generation vehicles [184]. As a result, the understanding of soot formation and oxidation within GDI engine configurations is of vital importance in formulating operating strategies for the mitigation of these ultra-fine PM. The fundamentals of soot processes are first briefly introduced in general. Detailed information regarding soot particulates formed during combustion processes can be found in other published reviews [28], [29], [185], [186]. Causes and mechanisms of soot particles generation in GDI engines are then discussed, followed by a review of the recent developmental works in the relevant modeling field.

Soot is generated as an undesirable by-product in the solid state of hydrocarbon combustion in many practical combustion devices. With no clear definition, it consists of roughly eight parts carbon and one part hydrogen in which the hydrogen content decreases as soot matures. Its formation is linked to the nucleation of carbonaceous fuel from the vapor phase to a solid phase under fuel-rich conditions at elevated temperatures. Hydrocarbons and other available molecules in the surroundings such as sulfur may adhere to the surface of particles [28]. The structure of soot aggregates is fractal in nature and the typical chain-like structures are made up of primary quasi-spherical particles [27], [187]. The size of spherules usually ranges from 15 to $50 \mathrm{~nm}$ in diameter [188]. There is a consensus agreed by most scientists engaged in soot research that the basic physical and chemical processes occurring during soot formation are similar regardless of the types of fuels and flames [186]. In other words, same formation mechanisms and growth constraints are applicable for soot originating from various combustion sources [189]. Therefore, knowledge derived from soot studies in simple laboratory flame configurations can be applied to extract information regarding complex combustion phenomena occurring in internal combustion engines.

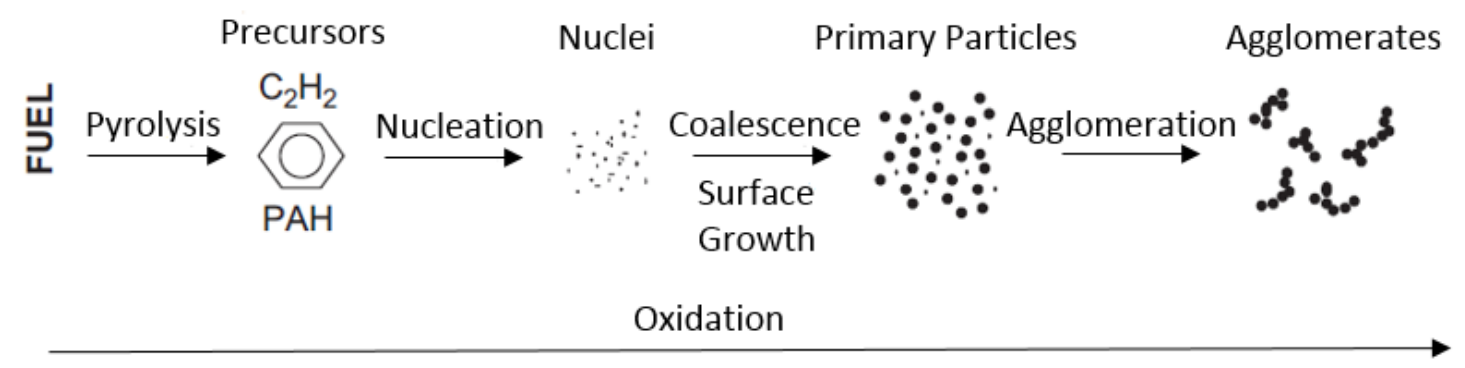

Figure 3 Steps in soot formation process from gas phase to solid particles [28].

Generally, the six commonly identified soot processes include fuel pyrolysis, nucleation, coalescence, surface growth, agglomeration and oxidation. It is worth noting that coagulation 
is also used interchangeably with coalescence by several authors. Distinctions between coagulation and agglomeration are addressed later. Figure 3 depicts the first five steps of soot formation, while soot oxidation takes place at any point during the entire process. Fuel pyrolysis involves alteration in molecular structure of fuels under high temperature without significant oxidation despite the presence of oxygen. Essentially, pyrolysis of all fuels generates the same species including unsaturated hydrocarbons, polyacetylenes, PAH and particularly acetylene $\left(\mathrm{C}_{2} \mathrm{H}_{2}\right)$. Some of the species act as soot precursors which are the building blocks of soot particles [28]. Nucleation refers to the inception of solid particles from gas-phase species in which its exact mechanism remains poorly understood [190]. Glassman [191] postulated the existence of a fuel-independent soot formation mechanism which possesses alternative routes to intermediate species. The propensity to soot would then be controlled by the initial rate of formation of the first and second ring structures. It is likely that the first ring is formed from two propynyl radicals and the aromatic ring transforms into a PAH structure with the addition of alkyl groups. Detailed description of PAH formation and their sequential growth is provided by Richter and Howard [100]. At present, the majority of soot models rely on the assumption of PAH as the soot precursors [29], [192]. Then, the nascent soot particles undergo surface growth which causes an increase in soot mass due to the addition of gas-phase species especially acetylene to the reactive surface of soot particles [28]. In the context, Frenklach and Wang [193] treated the surface growth of soot analogously to the planar growth of $\mathrm{PAH}$ through the $\mathrm{H}$-abstraction $/ \mathrm{C}_{2} \mathrm{H}_{2}$-addition (HACA) mechanism. It is observed that increasing particle growth decreases the tendency of soot particles to experience surface growth [190]. Larger particles undergo lower surface growth rates as a result of reduction in the availability of radical sites [194].

Coalescence or coagulation is the physical process in which relatively small particles collide and merge into a larger spheroid, thus reducing the number of particles while maintaining the same total combined mass [28]. The rate of coalescence is hence governed by the frequency of collisions between particles. Agglomeration takes place when existing particles stick together to form large groups of soot aggregates with fractal-like structures typically [28]. Nonetheless, it is noteworthy that not all collisions will lead to coalescence or agglomeration necessarily [195]. Oxidation converts carbon or more volatile hydrocarbons in the external particle layers into combustion products. In fact, partial oxidation of carbon to $\mathrm{CO}$ will cease the evolution of carbon into a soot particle even in a fuel-rich zone [28]. Soot particle oxidation is said to begin when the temperature reaches above $1300 \mathrm{~K}$ [191]. The two-stage process involves chemical attachment of oxygen to the surface and subsequent desorption of oxygen with fuel components from the surface. The contribution of oxidation species depends on the process and mixture state locally [28]. According to Bartok and Sarofim [194], oxidation under fuel-rich and stoichiometric conditions is most likely dominated by $\mathrm{OH}$ radicals whereas both $\mathrm{OH}$ and $\mathrm{O}_{2}$ oxidize soot under fuel-lean conditions. Other oxygenated species including the $\mathrm{O}$ atom, $\mathrm{H}_{2} \mathrm{O}$ and $\mathrm{CO}_{2}$ are important under certain conditions [196].

The study of PM formation and emission from diesel engines has been ongoing for several decades until today. On the other hand, the study of engine-out PM from gasoline engines is receiving much attention currently along with the relatively recent incorporation of direct injection strategy as GDI engines are found to be an important source of ultra-fine PM in the atmosphere. Many experimental studies [16], [17], [197]-[199] corroborated that the vast majority of soot (higher than $80 \%$ ) from the wall-guided GDI test engines can be considered 
as ultra-fine particles falling in the diameter range of 10 to $100 \mathrm{~nm}$ whereas above $55 \%$ is emitted in nucleation mode with diameter below $50 \mathrm{~nm}$. Consequently, PM studies for GDI engines rely heavily on the extensive works carried out in understanding soot processes in diesel engines due to certain similarities in chemical composition and soot morphology shared between both types of engines [200]. However, differences in particle size and number distributions from diesel soot were observed in a laboratory and on-road study performed for GDI vehicles [26]. Therefore, the identification of sources of soot formation and understanding of the mechanisms involved within GDI engine configurations are crucial for accurate modeling works and formulation of emission reduction strategies [38]. For GDI engines, soot is said to be generated mainly from three dominant sources: (1) imperfect mixture preparation including stratified-charge combustion with fuel-rich regions locally [17], [37], (2) piston- and wall-wetting due to liquid spray impingement as well as the resulting pool fires [23], [39], [201] and (3) diffusive burning of the remaining incompletely volatilized liquid fuel droplets [17]. Some studies have suggested that soot formation from pool fires may be the most prominent source for GDI engines as the soot particles produced survive until late in the cycle when the conditions for further soot oxidation are unfavorable (low temperature and absence of hydroxyl radicals) [22]. However, the relative importance of these PM formation mechanisms remains significantly linked to combustion chamber and injection system design as well as engine operating conditions [38].

It has been well established that the inherently short time available for the fuel to vaporize and mix with air properly during mixture preparation phase in GDI engines is responsible for the resulting charge inhomogeneity and wall-wetting effects in the cylinder [17], [37]. As a consequence of the inhomogeneous fuel mixture and the presence of locally fuel-rich regions, the particulate number emission in stratified charge operation were observed by Maricq et al. [17] to increase by approximately 10 to 40 times that of the homogeneous mixture. Meanwhile, extensive fuel impingement during fuel injection leads directly to the formation of fuel films within the cylinder. When the films remain until after combustion of the premixed charge has initiated, they ignite and burn with a diffusion flame event [201]. This phenomenon termed pool fire contributes primarily to soot formation in both homogenous and stratified modes [23] as well as to increased engine-out hydrocarbons and smoke emission in GDI engines [202]. Stevens and Steeper [201] demonstrated the production of PM from the pool fires induced by the fuel films through visualization with a laser-induced fluorescence imaging technique and laser elastic scattering of soot.

On a closer look, when a flame approaches a liquid film on the piston top, the regions swept by flame surface become burnt regions at high temperature. Although film vaporization is hence enhanced to form locally fuel-rich zones, fuel oxidation in the gas phase is somehow limited due to the lack of oxygen in the burnt regions. Through fuel pyrolysis, soot particles grow in high-temperature and fuel-rich regions and undergo subsequent oxidation in the $\mathrm{OH}$ rich combustion zone in the lean side of the flame, particularly diffusion flame in GDI engine setup. High amount of soot is more likely to be produced in the rich areas near the wall films [39]. Furthermore, a study by Fujimoto et al. [203] pointed out that fuel spray impingement and wall wetting might lead to lubricant oil dilution which eventually became another potential source of soot formation in GDI engines. On the other hand, rich combustion arising from the charring of remaining liquid droplets in the cylinder is theorized to be another important source of engine-out PM for late injection timings [17]. 


\subsubsection{Soot Modeling of GDI Engines}

While advanced optical techniques allow the visualization and study of in-cylinder processes of GDI engines, the major drawback is that only limited geometric specifications and operating conditions can be examined due to costly maintenance and problems caused by thermal evolution and blow-by [37]. Thus, the application of CFD emerges as a powerful alternative to acquire deeper understanding of engine performance across a wide range of varying operating parameters and designs. Soot modeling in internal combustion engine simulations is relatively challenging due to the complex structure, composition and chemical interactions of soot particles in their formation and oxidation mechanisms [106]. Generally, the models of soot formation and oxidation are categorized into purely empirical correlations, semi-empirical approaches and detailed models, in order of growing complexity [28], [196].

Empirical models typically predict trends in soot loadings using direct correlation to experimental measurements collected under premixed and diffusion flames. The general validity of such models is however uncertain as the modeling constants are adjusted against a set of specified baseline measurements to provide good agreement [196]. The simplest models utilize one rate expression for soot formation and another one for soot oxidation [28]. Semi-empirical models incorporate rate equations for reactions involving soot precursors and soot particles with input from experimental data. They tend to include dominant physicochemical phenomena and rely on simplified chemistry to compute the rate equations. Similarly, the application of ad-hoc models is restricted inherently to specific conditions under which the rates are obtained [196]. Detailed models involve solving the rate equations for elementary reactions contributing to soot by usually treating the entire panoply of phenomena during net soot formation. Often, detailed descriptions of kinetics for PAH and soot particles are required [196]. For example, the works by Frenklach et al. [193], [204] covered comprehensive soot modeling from fuel pyrolysis to soot oxidation in detail. Despite the broad applicability and generality of detailed models, the associated high computational cost obscures their implementation into multi-dimensional CFD simulations with complex geometric configurations [28].

Overall, the inherent superiority and efficacy of various soot models proposed are difficult to be evaluated as most models are calibrated with specific experimental measurements. Kennedy [196] recommended the establishment of universally acceptable experimental data sets to which the development of soot models can be based upon. To model soot processes within engine configurations, the trade-off between computational cost and prediction accuracy justifies the common selection of semi-empirical models. Nonetheless, the boundary distinguishing between semi-empirical and detailed approaches is not clearly defined with many models shifting to the detailed type as progress is continuously made to incorporate fuel chemistry. Apart from soot kinetics, soot particle dynamics need to be addressed in the modeling works through the particle size distribution function (PSDF). Generally, three approaches are commonly utilized to extract information regarding the population of particles generated [205]. The first approach is the Monte Carlo method whereby the soot particles are represented by a stochastic particle system [206]. Secondly, the soot particles are discretized into bins or sections where the evolution equations are solved in the sectional methods [207], [208]. In the third approach known as the method of moments, evolution equations are computed for moments of the PSDFs which are expressed as mean quantities [209]. The various soot models formulated and adapted for numerical simulations of soot processes in 
GDI engines are summarized and appraised, to the authors' best knowledge, in Table 6 . Additional information including precursor species and variables solved is also tabulated. 
Table 6 Concise description of soot models adapted for soot modeling studies in GDI engines.

\begin{tabular}{|c|c|c|c|c|c|}
\hline Year & Author(s); Soot model & Precursor & Description & Variable solved & Limitation \\
\hline 2002 & $\begin{array}{l}\text { Wallesten et al. [210]; } \\
\text { Kennedy-Hiroyasu- } \\
\text { Magnussen soot model }\end{array}$ & Fuel vapor & $\begin{array}{l}\text { - The three-stage model includes nucleation, surface growth and } \\
\text { oxidation. } \\
\text { - The model is corrected based on the two-step empirical soot model } \\
\text { proposed by Hiroyasu. }\end{array}$ & Mass fraction & $\begin{array}{l}\quad \text { Particle coagulation is not considered. } \\
\text { Exaggerated trends in soot mass fraction are } \\
\text { obtained for different injection timings. }\end{array}$ \\
\hline 2011 & $\begin{array}{l}\text { Etheridge et al. [211]; } \\
\text { Detailed population } \\
\text { balance soot model }\end{array}$ & $\mathrm{A}_{4}$ & $\begin{array}{l}\text { - The model includes inception, condensation, surface growth, } \\
\text { coagulation and oxidation. } \\
\text { - The population of soot aggregates is represented by an ensemble of } \\
\text { stochastic soot particles. } \\
\text { - The equations are solved using Monte Carlo methods. }\end{array}$ & $\begin{array}{l}\text { Mass, number } \\
\text { density, volume } \\
\text { fraction, surface } \\
\text { area, } \\
\text { composition }\end{array}$ & $\begin{array}{l}\text { - The engine model is spatially zero dimensional. } \\
\text { - It is computationally intractable with sectional } \\
\text { or moment methods. }\end{array}$ \\
\hline 2012 & $\begin{array}{l}\text { Kwon et al. [212]; } \\
\text { Phenomenological } \\
\text { soot model }\end{array}$ & $\begin{array}{l}\text { Fuel } \\
\text { radicals }\end{array}$ & $\begin{array}{l}\text { - The model includes pyrolysis, inception, surface growth, coagulation } \\
\text { and oxidation. } \\
\text { - Soot processes are described through global rate expressions. } \\
\text { - The collision frequency factors of radical and acetylene formation } \\
\text { processes are tuned. }\end{array}$ & $\begin{array}{l}\text { Number density, } \\
\text { species } \\
\text { concentration, } \\
\text { volume fraction }\end{array}$ & $\begin{array}{l}\text { - It is assumed that oxidation does not affect the } \\
\text { number density of particles. } \\
\text { - The model is commonly suited for non- } \\
\text { premixed combustion. } \\
\text { - Average particle diameter is estimated based on } \\
\text { the monodisperse assumption. }\end{array}$ \\
\hline 2014 & $\begin{array}{l}\text { Kim et al. [213]; } \\
\text { Phenomenological } \\
\text { soot model }\end{array}$ & $\mathrm{C}_{2} \mathrm{H}_{2}$ & $\begin{array}{l}\text { - The model consists of four steps including nucleation, surface growth, } \\
\text { coagulation and oxidation. } \\
\text { - The rate constant of particle coagulation is revised. }\end{array}$ & $\begin{array}{l}\text { Mass fraction, } \\
\text { number density, } \\
\text { average size }\end{array}$ & $\begin{array}{l}\text { emission predicted by the } \\
\text { n. }\end{array}$ \\
\hline 2014 & $\begin{array}{l}\text { Naik et al. [214]; } \\
\text { Pseudo-gas soot model }\end{array}$ & $\mathrm{A}_{4}$ & $\begin{array}{l}\text { - The model contains seven steps which describe nucleation, surface } \\
\text { growth and oxidation. } \\
\text { - The rate constants of reactions are altered. } \\
\text { - The model is included within the fuel mechanism. }\end{array}$ & Mass & $\begin{array}{l}\text { - } \quad \text { Particle coagulation is not considered. } \\
\text { Number density and size distribution of soot } \\
\text { particles cannot be determined. }\end{array}$ \\
\hline 2014 & $\begin{array}{l}\text { Liang et al. [215]; } \\
\text { Detailed soot-particle } \\
\text { model }\end{array}$ & $\mathrm{A}_{4}$ & $\begin{array}{l}\text { - The model includes nucleation, surface growth, coagulation and } \\
\text { oxidation. } \\
\text { - The surface processes are modelled through a surface chemistry } \\
\text { mechanism. } \\
\text { The evolution of soot particles is solved through the method of } \\
\text { moments. }\end{array}$ & $\begin{array}{l}\text { Number density, } \\
\text { volume fraction, } \\
\text { surface area, } \\
\text { average size }\end{array}$ & $\begin{array}{l}\text { - Only average properties of the population of } \\
\text { soot particles are obtainable. } \\
\text { - The results of soot emission lack validations for } \\
\text { engine configurations. }\end{array}$ \\
\hline 2014 & $\begin{array}{lr}\text { Jiao and Reitz } & {[39] ;} \\
\text { Semi-detailed } & \text { soot } \\
\text { model } & \end{array}$ & $\mathrm{A}_{4}$ & $\begin{array}{l}\text { - The model includes nucleation, surface growth, coagulation and } \\
\text { oxidation. } \\
\text { - Transport equations are solved including the effects of thermophoretic } \\
\text { diffusion. }\end{array}$ & $\begin{array}{ll}\text { Mass, number } \\
\text { density }\end{array}$ & $\begin{array}{l}\quad \text { The effect of soot radiation is not considered. } \\
\text { The results of soot emission lack validations for } \\
\text { engine configurations. }\end{array}$ \\
\hline 2016 & $\begin{array}{l}\text { Wang et al. [216]; } \\
\text { Detailed population } \\
\text { balance soot model }\end{array}$ & $\mathrm{A}_{7}$ & $\begin{array}{l}\text { - The model includes inception, condensation, surface growth, } \\
\text { coagulation and oxidation. } \\
\text { - The equations are solved using Monte Carlo methods. } \\
\text { - The engine model is extended to include spray impingement and wall } \\
\text { film evaporation. }\end{array}$ & $\begin{array}{l}\text { Mass, number } \\
\text { density, volume } \\
\text { fraction, surface } \\
\text { area, } \\
\text { composition }\end{array}$ & $\begin{array}{l}\text { - The engine model is spatially zero dimensional. } \\
\text { - It is computationally intractable with sectional } \\
\text { or moment methods. } \\
\text { - The size of particles in the main mode and total } \\
\text { mass are under-predicted. }\end{array}$ \\
\hline
\end{tabular}


The early work by Wallesten et al. [210] examined combustion modeling in a GDI engine under both homogeneous and stratified charge conditions. With the FSC model coupled with a reaction mechanism for pure iso-octane, combustion phasing for different operating conditions was reproduced by comparing computed pressure curves to the measured ones. At the same time, the Kennedy-Hiroyasu-Magnussen model was applied to account for the corresponding soot formation processes. The trend of decreasing soot mass fractions with advancing start of injection was captured qualitatively, but leading to an over-prediction under stratified charge combustion. The substantial tuning effort required restricted the soot model to roughly indicate soot formation regions and general trends rather than to be an effective predictive tool for soot emission. It is not until recently that soot modeling of GDI engines has drawn significant attention and research to investigate the relevant mechanisms in depth.

Detailed soot modeling in a spark-ignition engine was first attempted by Etheridge et al. [211] with the application of stochastic reactor model (SRM) and a highly detailed soot model. The integrated models were initially calibrated based on a GDI engine with early injection strategy, before utilizing them to simulate soot formation under stratified charge conditions. The soot model involved a detailed set of population balance equations which were solved through Monte Carlo methods to describe particle morphology and chemical composition of soot [192]. It was found that retarding the injection timings led to an increase in both number density and size of particles which matched the experimental trends of exhaust gas measurements. The observation was due to higher charge stratification which in turn resulted in incomplete combustion in locally fuel-rich regions [211]. Most recently, Wang et al. [216] employed the same soot model and extended the engine model to include spray impingement and wall film evaporation to evaluate the wall film as a source of soot formation. The chemistry calculations were performed using a detailed PRF mechanism consisting of 208 species among 1002 reactions. However, unlike the previous work which used acetylene as the soot precursor [211], the nucleation of a soot particle was modelled by dimerization of coronene, a seven-ring PAH $\left(\mathrm{A}_{7}\right)$. Although the simulated particle size distribution lay within the same order of magnitude as the experimental measurements, particle size in the main mode of distribution was under-predicted by nearly a factor of two, causing lower total mass of soot computed. Hence, the results called for further model tuning and improvements. By tracing the evolution of particles in equivalence ratio-temperature diagrams, the study demonstrated that soot was mainly formed in the rich mixture near the wall caused by spray impingement [216].

Meanwhile, the adaption of multi-step phenomenological models for soot modeling in GDI engines was seen in the works by Kwon et al. [212] and Kim et al. [213] who combined flamelet models for premixed and diffusion flames within GDI engine setups. Kwon et al. [212] induced a presumed shape of PDF approach to extend the flamelet model for partially premixed conditions along with pre-calculated laminar flame speeds from a TRF mechanism containing 120 species and 677 reactions. Furthermore, they modelled soot formation as a post-flame reaction with a phenomenological model proposed by Fusco et al. [217] for diesel engines. In the model, the processes of pyrolysis, inception, surface growth, coagulation and oxidation were described as global rate expressions with the rate constants fit within the same range as those of elementary soot kinetic reactions. In matching the experimental data, collision frequency factors of radical and acetylene formation were tuned during the 
simulations. Computed soot number density and volume fraction increased with higher intake pressure and showed good agreement with experimental measurements. This was because higher intake pressure was associated with higher in-cylinder temperature which favored the formation of soot radical and growth species [212]. Following a relatively similar approach for combustion modeling, Kim et al. [213] integrated a flame kernel development model with the G-equation model to characterize the turbulent flame propagation. As the multi-step soot model of Fusco et al. [217] was suited for non-premixed combustion, a four-step phenomenological soot model based on the concepts of El-Asrag et al. [218] was applied for partially premixed combustion in GDI engines. The model included nucleation and surface growth via acetylene, coagulation as well as oxidation by molecular oxygen and hydroxyl radicals. Nonetheless, the results on soot emission did not allow an evaluation of the model predictive capabilities.

The modeling of soot formation and oxidation in GDI engines was also carried out by the research group at Reaction Design using the FORTÉ CFD software [214], [215]. Full cycle simulations of a GDI engine from intake valve opening to exhaust valve opening were performed by Naik et al. [214] to examine combustion and emission behaviors. To account for the detailed chemistry effects of gasoline, a seven-component surrogate was formulated with 230 species and 1740 reactions. The updated soot model treated soot as a pseudo-gasphase species which only increased the size of fuel mechanism by two species, thus maintaining computational efficiency. Soot nucleation, growth and oxidation were described in seven steps in the model. Soot oxidation by nitrogen dioxide and sensitization by steam were also included. The soot model was validated in terms of species concentrations and soot mass fraction of premixed ethylene flames. For engine cases, good agreement was observed between simulated and measured in-cylinder planar averaged soot volume fraction. The results showed that retarding ignition timing caused an increased level of soot volume fraction as seen experimentally. The results of soot volume fraction were, however, planar averaged (two-dimensional) rather than cylinder-averaged. In a study by Liang et al. [215], a detailed soot particle model was integrated with particle tracking through the method of moments. The detailed soot model was developed by Puduppakkam et al. [219] and validated against soot particle size data in laboratory-scale flames of single-component fuels including $\mathrm{n}$-heptane and toluene. The model was first applied for spray combustion of n-heptane and a jet fuel surrogate in a constant volume chamber to estimate lift-off lengths and soot volume fractions. Subsequently, the model simulated soot processes in a spray-guided GDI engine by illustrating the time evolution of soot cloud at certain crank angles [215]. The engine results lacked validations from experimental measurements or optical diagnostics. Particularly, the study demonstrated that soot formation was mainly a post-flame phenomenon within GDI engine configurations as also indicated in previous works [212], [213]. Continuation of the work was reported recently by Puduppakkam et al. [220] to predict soot emission of GDI engines. While soot trend was correctly captured by the model, the magnitudes of average soot volume fraction were over-predicted by a factor of three as compared with the experimental measurements obtained in a planar laser sheet.

Jiao and Reitz [39] used CFD modeling to investigate the significance of wall films as a soot source in GDI engines. The gasoline fuel was represented by a ternary mixture of TRF surrogate comprising 89 species and 506 reactions. In the study, a semi-detailed soot model based on the formulation by Vishwanathan and Reitz [221] was adapted. The improved 
model had been utilized successfully for a homogeneous charge SI engine to predict incylinder soot particle distributions [222]. The model assumed that the smallest incipient particle size was $1.25 \mathrm{~nm}$ and experienced surface growth from both acetylene and PAH. Particle coagulation was modelled through the normal square dependence. Soot oxidation was described to occur via oxygen and hydroxyl radicals. In simulations of spray combustion for n-heptane, trends and magnitudes of peak soot volume fraction were estimated reasonably well with changes in ambient conditions. For engine setups, the operating conditions included lean-burn stratified charge combustion and late injection strategy. The results for spray, mixture distributions, combustion and emission were compared to those employing the twostep soot model proposed by Hiroyasu. Soot was formed and the total mass increased continuously for the former while no soot mass was computed for the latter [39]. The improved semi-detailed model was able to correlate soot formation in the GDI engine to the vaporization of wall films as observed in experiments. In a subsequent study [223], Jiao and Reitz investigated the effects of engine operating parameters including fuel composition, spray cone angle, injection timing and wall temperature on soot emission in GDI engines. Particularly, the significance of using multi-component fuel surrogates was highlighted as the heavy components (low volatility) caused the formation of wall films which then contributed to soot emission during combustion.

Generally, the study of soot modeling in GDI engine configurations is still in its infancy hitherto with relatively limited works performed to characterize the associated panoply of soot formation and oxidation processes. Numerous studies affirm evaporation of wall films caused by spray impingement as the main source of soot formation for GDI engines through CFD simulations of in-cylinder combustion events. From the literature, it is apparent that most soot models adapted are based on formulations previously applied to diesel engine combustion and/or derived from laboratory-scale flame configurations. Owing to the knowledge gained regarding the importance of PAH as soot precursor species, the recent soot models utilized for GDI engines consider nucleation of soot particles via pyrene $\left(\mathrm{A}_{4}\right)$ [39], [214], [215] and even coronene [216], as shown in Table 6. Moreover, the soot models are more comprehensive in nature in which the basic phases including inception, surface growth, coagulation and oxidation are typically modelled as opposed to the conventional oversimplified empirical approaches. While the trends of soot emission are often captured reasonably well, quantitative agreement of modeling results with experimental measurements is relatively poor with significant deviations observed in the particle size distributions under complex engine geometries. Hence, accuracy in model prediction of soot emission levels needs to be enhanced continuously to improve robustness and applicability across a wide range of operating conditions pertinent to GDI engines. The soot models should address the differences between PM generated from diesel and gasoline engines within their formulation. More importantly, the computational results require consistent validations against optical images and engine-out measurements from experimental GDI engine test-bed facilities to ensure model reliability.

\section{Conclusions}

Being a promising technology in the automotive industry, GDI engines hold great potential for enhanced fuel economy as compared to the conventional PFI engines. Nevertheless, the emission of PM by this type of engines remains one of the main challenges faced by major car manufacturers globally. The increasingly stringent standards on engine exhaust emissions 
provide focus and imperative for the definition of improved designs and control strategies aimed at reducing ultra-fine PM. While experimental and optical techniques are paving the way to significant advancements with detailed examination on in-cylinder events, numerical analysis through multi-dimensional CFD modeling plays an important role to facilitate the understanding of complex engine phenomena in a timely and cost-effective manner. Within the context, successful simulations of engine processes often rely on accurate representation of practical fuels in terms of their chemical kinetics. The present study summarizes recent developments in chemical kinetic modeling of gasoline fuels for application in CFD modeling of GDI engines, with a specific emphasis on the associated soot processes.

Due to the quasi-continuous spectrum of hydrocarbon constituents, gasoline fuels are typically represented as surrogate mechanisms. Although iso-octane has been a popular candidate for single-component fuel models, PRF mechanisms are also widely utilized as the octane rating of gasoline is established based on the composition of the two reference fuel species. Currently, there is a shift of focus towards the application of TRF models to account for the aromatic compounds and fuel sensitivity. Moreover, paralleling the works in blending gasoline with various additives, more complex reaction mechanisms are being constructed with multi-component nature. Several additional fuel components include 1-hexene, 2pentene, DIB and ethanol. The incorporation of such multi-component surrogates into CFD modeling studies is, however, fairly limited due to the enormous computing power incurred. Hence, the TRF reaction mechanisms can be considered more appropriately suited for multidimensional CFD simulations and so they are to remain in the foreseeable future. This is because the three surrogate components represent the hydrocarbon classes of alkanes and aromatics which are present largely in real gasoline fuels. Despite the abundance of fuel mechanisms developed, most models are validated in HCCI engine conditions which deviate from those of GDI engines. Hence, the performance of fuel models should be investigated under engine-like or engine operating conditions of GDI engine configurations.

Over the years, significant research efforts have been directed at understanding the complex in-cylinder phenomena of GDI engines for both types of homogeneous and stratified charge combustion. Stratified charge combustion offers potentially greater fuel efficiency, but at the same time greater complications in modeling due to its two-stage combustion behavior. It involves an initial premixed turbulent flame propagation, followed by a secondary diffusioncontrolled phase. Combustion models aiming to resolve the two-phase combustion are normally addressed to as partially premixed combustion models which feature local stratifications due to poor mixture preparation. Among all, the flamelet approach which takes into account both chemistry and turbulence effects continues to be a highly potential option for modeling combustion in GDI systems. Under the concept, models such as CFM, ECFM and G-equation model have been widely applied with remarkable success. Importantly, the future direction should be at characterizing the turbulent flame propagation accurately by addressing the induced in-cylinder mixture inhomogeneity and capturing the detailed chemistry-turbulence interaction, along with the incorporation of complex fuel mechanisms which better resemble the real fuels.

Comparatively, soot modeling studies for GDI engines are somehow limited with scant success achieved for accurate prediction of soot emission levels. However, the area is receiving much attention among the CFD practitioners as a consequence of the detrimental effects of ultra-fine PM to human health. Many soot models applied to GDI engine 
combustion and the underlying principles behind them are derived from ongoing works for diesel combustion systems and simple flame configurations. The process of re-adaptaton must carefully consider the inherent difference between GDI and diesel combustion, not only in terms of fuel type and typical composition, but also in terms of mixture strength, combustion temperature and expected exhaust gas composition. The expected substantial model tuning will need to account for the fundamental differences and translate these into an appropriate balance between the relative weights of the various soot mechanisms within multi-step soot models. Multi-step soot models cover important phases including nucleation, surface growth, coagulation and oxidation which offer higher comprehensiveness than oversimplified empirical models. In other words, multi-step semi-empirical models provide a relatively complete characterization of soot processes at affordable computational cost and effort, considering the trade-off between accuracy and applicability. Therefore, the use of multi-step models would potentially become the norm in soot modeling within engine configurations in general with increasing modeling details to achieve accurate estimations. Furthermore, more reliable soot precursor species are preferred, especially PAHs including pyrene and even coronene as evidenced in the recent modeling works. Generically speaking, overall trends in soot emission from GDI engines have been well reproduced currently with quantitative deviations observed for computation of particle size distributions. Consequently, further research into developing and improving soot models tailored for GDI engine applications is very much required with validations against optical and experimental data from test engines across a wide range of operating conditions. 


\section{Nomenclature}

$3 \mathrm{D}=$ three-dimensional

$\mathrm{A}_{4}=$ pyrene

$\mathrm{A}_{7}=$ coronene

AKTIM $=$ arc and kernel tracking ignition model

$\mathrm{BML}=$ Bray-Moss-Libby

$\mathrm{C}_{2} \mathrm{H}_{2}=$ acetylene

$\mathrm{CFD}=$ computational fluid dynamics

$\mathrm{CFM}=$ coherent flame model

$\mathrm{CFR}=$ cooperative fuel research

$\mathrm{CMC}=$ continuous multi-component

$\mathrm{CTC}=$ characteristic-time combustion

$\mathrm{DDM}=$ discrete droplet model

DIB $=$ diisobutylene

DISI $=$ direct injection spark ignition

$\mathrm{DMC}=$ discrete multi-component

$\mathrm{DNS}=$ direct numerical simulation

DPF $=$ diesel particulate filter

DPIK $=$ discrete particle ignition kernel

$\mathrm{EBM}=$ eddy-breakup model

ECFM $=$ extended coherent flame model

$\mathrm{EDM}=$ eddy-dissipation model

$\mathrm{EGR}=$ exhaust gas recirculation

$\mathrm{FSC}=$ flame speed closure

GDI $=$ gasoline direct injection

$\mathrm{HACA}=\mathrm{H}$-abstraction $/ \mathrm{C}_{2} \mathrm{H}_{2}$-addition

$\mathrm{HCCI}=$ homogeneous charge compression ignition

ID = ignition delay

IMEP $=$ indicated mean effective pressure

$\mathrm{JSR}=$ jet-stirred reactor

KH-RT $=$ Kelvin-Helmholtz and Rayleigh Taylor

LES = large eddy simulation
LISA $=$ linearized instability sheet atomization

LLNL $=$ Lawrence Livermore National

Laboratory

$\mathrm{MCH}=$ methylcyclohexane

$\mathrm{MON}=$ motor octane number

$\mathrm{NO}_{\mathrm{x}}=$ nitric oxides

$\mathrm{OI}=$ octane index

$\mathrm{ON}=$ octane number

OPPDIF $=$ opposed-flow diffusion flames

$\mathrm{PAH}=$ polycyclic aromatic hydrocarbons

$\mathrm{PDF}=$ probability density function

PFI $=$ port fuel injection

$\mathrm{PM}=$ particulate matter

PREMIX = premixed laminar flames

$\mathrm{PRF}=$ primary reference fuel

PSDF $=$ particle size distribution function

PSR $=$ perfectly stirred reactor

RANS $=$ Reynolds-averaged Navier-Stokes

$\mathrm{RCM}=$ rapid compression machine

$\mathrm{RNG}=$ re-normalization group

$\mathrm{RON}=$ research octane number

$\mathrm{SI}=$ spark ignition

$\mathrm{s}_{\mathrm{L}}=$ laminar flame speed

$\mathrm{SMD}=$ Sauter mean diameter

SparkCIMM = spark channel ignition

monitoring model

$\mathrm{SRM}=$ stochastic reactor model

$\mathrm{ST}=$ shock tube

$\mathrm{TAB}=$ Taylor analogy breakup

$\mathrm{TRF}=$ ternary reference fuel

$\mathrm{UHC}=$ unburned hydrocarbons

VOF $=$ volume of fluid

VPFR $=$ variable pressure flow reactor 


\section{References}

[1] D. D. Brehob, J. E. Fleming, M. Haghgooie, and R. A. Stein, "Stratified-Charge Engine Fuel Economy and Emission Characteristics," SAE Tech. Pap., Oct. 1998.

[2] V. Ganesan, Internal Combustion Engines, 4th ed. New Delhi: Tata McGraw-Hill, 2012.

[3] F. Zhao, M.-C. Lai, and D. . Harrington, "Automotive spark-ignited direct-injection gasoline engines," Prog. Energy Combust. Sci., vol. 25, no. 5, pp. 437-562, Oct. 1999.

[4] F. Bonatesta, G. Altamore, J. Kalsi, and M. Cary, "Fuel economy analysis of part-load variable camshaft timing strategies in two modern small-capacity spark ignition engines," Appl. Energy, vol. 164, pp. 475-491, Feb. 2016.

[5] R. Ortmann, S. Arndt, J. Raimann, R. Grzeszik, and G. Würfel, "Methods and Analysis of Fuel Injection, Mixture Preparation and Charge Stratification in Different Direct Injected SI Engines," SAE Tech. Pap., Mar. 2001.

[6] M. B. Çelik and B. Ozdalyan, "Gasoline Direct Injection," in Fuel Injection, D. Siano, Ed. Sciyo, 2010.

[7] P. Ericsson and A. Samson, "Characterization of Particulate Emissions Propagating in the Exhaust Line for Spark Ignited Engines," SAE Tech. Pap., Nov. 2009.

[8] J. Andersson, B. Giechaskiel, R. Muñoz-Bueno, E. Sandbach, and P. Dilara, "Particle Measurement Programme (PMP) Light-duty Inter-laboratory Correlation Exercise (ILCE_LD) Final Report,” 2007.

[9] B. R. Graskow, D. B. Kittelson, I. S. Abdul-Khalek, M. R. Ahmadi, and J. E. Morris, "Characterization of Exhaust Particulate Emissions from a Spark Ignition Engine," SAE Tech. Pap., Feb. 1998.

[10] M. Braisher, R. Stone, and P. Price, "Particle Number Emissions from a Range of European Vehicles," SAE Tech. Pap., Apr. 2010.

[11] P. Penttinen, K. L. Timonen, P. Tiittanen, A. Mirme, J. Ruuskanen, and J. Pekkanen, "Ultrafine particles in urban air and respiratory health among adult asthmatics.," Eur. Respir. J., vol. 17, no. 3, pp. 428-35, Mar. 2001.

[12] A. Peters, B. Veronesi, L. Calderón-Garcidueñas, P. Gehr, L. C. Chen, M. Geiser, W. Reed, B. RothenRutishauser, S. Schürch, and H. Schulz, "Translocation and potential neurological effects of fine and ultrafine particles a critical update.," Part. Fibre Toxicol., vol. 3, no. 1, p. 13, Jan. 2006.

[13] D. Brugge, J. L. Durant, and C. Rioux, "Near-highway pollutants in motor vehicle exhaust: a review of epidemiologic evidence of cardiac and pulmonary health risks.," Environ. Health, vol. 6, p. 23, Jan. 2007.

[14] J. Heyder, "Deposition of Inhaled Particles in the Human Respiratory Tract and Consequences for Regional Targeting in Respiratory Drug Delivery," in Proceedings of the American Thoracic Society, 2004, vol. 1, pp. 315-320.

[15] S. Ashley, "Attacking GDI engine particulate emissions," Automotive Engineering Magazine, Dec-2014.

[16] K. Choi, J. Kim, C.-L. Myung, M. Lee, S. Kwon, Y. Lee, and S. Park, "Effect of the mixture preparation on the nanoparticle characteristics of gasoline direct-injection vehicles," Proc. Inst. Mech. Eng. Part D J. Automob. Eng., vol. 226, no. 11, pp. 1514-1524, May 2012.

[17] M. M. Maricq, D. H. Podsiadlik, D. D. Brehob, and M. Haghgooie, "Particulate Emissions from a DirectInjection Spark-Ignition (DISI) Engine," SAE Tech. Pap., May 1999.

[18] I. Whelan, S. Samuel, and A. E. Hassaneen, "The Effect of Fuel Temperature on Particulate Matter Formation in Gasoline Direct-Injection Engines," SAE Int. J. Fuels Lubr., vol. 3, no. 2, pp. 67-76, May 2010.

[19] C. Wang, H. Xu, J. M. Herreros, J. Wang, and R. Cracknell, "Impact of fuel and injection system on particle emissions from a GDI engine," Appl. Energy, vol. 132, pp. 178-191, Nov. 2014.

[20] F. Bonatesta, E. Chiappetta, and A. La Rocca, "Part-load particulate matter from a GDI engine and the connection with combustion characteristics," Appl. Energy, vol. 124, pp. 366-376, Jul. 2014.

[21] L. P. Wyszynnski, R. Aboagye, R. Stone, and G. Kalghatgi, "Combustion Imaging and Analysis in a Gasoline Direct Injection Engine," SAE Tech. Pap., Mar. 2004.

[22] B. D. Stojkovic, T. D. Fansler, M. C. Drake, and V. Sick, "High-speed imaging of $\mathrm{OH}^{*}$ and soot temperature and concentration in a stratified-charge direct-injection gasoline engine," Proc. Combust. Inst., vol. 30, no. 2, pp. 2657-2665, Jan. 2005.

[23] A. Velji, K. Yeom, U. Wagner, U. Spicher, M. Rossbach, R. Suntz, and H. Bockhorn, "Investigations of the Formation and Oxidation of Soot Inside a Direct Injection Spark Ignition Engine Using Advanced LaserTechniques," SAE Tech. Pap., Apr. 2010.

[24] W. J. Pitz, N. P. Cernansky, F. L. Dryer, F. N. Egolfopoulos, J. T. Farrell, D. G. Friend, and H. Pitsch, "Development of an Experimental Database and Chemical Kinetic Models for Surrogate Gasoline Fuels," 
SAE Tech. Pap., Apr. 2007.

[25] D. C. Haworth, "A Review of Turbulent Combustion Modeling for Multidimensional In-Cylinder CFD," SAE Tech. Pap., Apr. 2005.

[26] P. Karjalainen, L. Pirjola, J. Heikkilä, T. Lähde, T. Tzamkiozis, L. Ntziachristos, J. Keskinen, and T. Rönkkö, "Exhaust particles of modern gasoline vehicles: A laboratory and an on-road study," Atmos. Environ., vol. 97, pp. 262-270, Nov. 2014.

[27] A. La Rocca, F. Bonatesta, M. W. Fay, and F. Campanella, "Characterisation of soot in oil from a gasoline direct injection engine using Transmission Electron Microscopy," Tribol. Int., vol. 86, pp. 77-84, Jun. 2015.

[28] D. R. Tree and K. I. Svensson, "Soot processes in compression ignition engines," Prog. Energy Combust. Sci., vol. 33, no. 3, pp. 272-309, Jun. 2007.

[29] J. Xi and B.-J. Zhong, "Soot in Diesel Combustion Systems," Chem. Eng. Technol., vol. 29, no. 6, pp. 665673, Jun. 2006.

[30] H. Omidvarborna, A. Kumar, and D.-S. Kim, "Recent studies on soot modeling for diesel combustion," Renew. Sustain. Energy Rev., vol. 48, pp. 635-647, Aug. 2015.

[31] G. B. Machado, J. E. M. Barros, S. L. Braga, C. V. M. Braga, E. J. de Oliveira, A. H. M. da F. T. da Silva, and L. de O. Carvalho, "Investigations on surrogate fuels for high-octane oxygenated gasolines," Fuel, vol. 90, no. 2, pp. 640-646, Feb. 2011.

[32] L. Cai and H. Pitsch, "Optimized chemical mechanism for combustion of gasoline surrogate fuels," Combust. Flame, vol. 162, no. 5, pp. 1623-1637, Jan. 2015.

[33] M. Mehl, J. Y. Chen, W. J. Pitz, S. M. Sarathy, and C. K. Westbrook, "An approach for formulating surrogates for gasoline with application toward a reduced surrogate mechanism for CFD engine modeling," Energy and Fuels, vol. 25, no. 11, pp. 5215-5223, Nov. 2011.

[34] J. M. Simmie, "Detailed chemical kinetic models for the combustion of hydrocarbon fuels," Prog. Energy Combust. Sci., vol. 29, no. 6, pp. 599-634, Jan. 2003.

[35] F. Battin-Leclerc, "Detailed chemical kinetic models for the low-temperature combustion of hydrocarbons with application to gasoline and diesel fuel surrogates," Prog. Energy Combust. Sci., vol. 34, no. 4, pp. 440498, Aug. 2008.

[36] B. Galmiche, F. Halter, and F. Foucher, "Effects of high pressure, high temperature and dilution on laminar burning velocities and Markstein lengths of iso-octane/air mixtures," Combust. Flame, vol. 159, no. 11, pp. 3286-3299, Nov. 2012.

[37] T. Lucchini, G. D’Errico, A. Onorati, G. Bonandrini, L. Venturoli, and R. Di Gioia, "Development and application of a computational fluid dynamics methodology to predict fuel-air mixing and sources of soot formation in gasoline direct injection engines," Int. J. Engine Res., vol. 15, no. 5, pp. 581-596, Oct. 2013.

[38] F. Bonatesta, S. La Rocca, E. Hopkins, and D. Bell, "Application of Computational Fluid Dynamics to Explore the Sources of Soot Formation in a Gasoline Direct Injection Engine," SAE Tech. Pap., Oct. 2014.

[39] Q. Jiao and R. D. Reitz, "Modeling soot emissions from wall films in a direct-injection spark-ignition engine," Int. J. Engine Res., vol. 16, no. 8, pp. 994-1013, Dec. 2014.

[40] G. T. Kalghatgi, K. Nakata, and K. Mogi, "Octane Appetite Studies in Direct Injection Spark Ignition (DISI) Engines," SAE Tech. Pap., Apr. 2005.

[41] G. T. Kalghatgi, "Auto-Ignition Quality of Practical Fuels and Implications for Fuel Requirements of Future SI and HCCI Engines," SAE Tech. Pap., Apr. 2005.

[42] G. Edgar, "Measurement of Knock Characteristics of Gasoline in Terms of a Standard Fuel," Ind. Eng. Chem., vol. 19, no. 1, pp. 145-146, Jan. 1927.

[43] N. Morgan, A. Smallbone, A. Bhave, M. Kraft, R. Cracknell, and G. Kalghatgi, "Mapping surrogate gasoline compositions into RON/MON space," Combust. Flame, vol. 157, no. 6, pp. 1122-1131, Jun. 2010.

[44] "Standard Test Method for Research Octane Number of Spark-Ignition Engine Fuel," West Conshohocken, 2013.

[45] "Standard Test Method for Motor Octane Number of Spark-Ignition Engine Fuel," West Conshohocken, 2014.

[46] D. Bradley and R. A. Head, "Engine autoignition: The relationship between octane numbers and autoignition delay times," Combust. Flame, vol. 147, no. 3, pp. 171-184, Nov. 2006.

[47] S. Yan, Y.-J. Jiang, N. D. Marsh, E. G. Eddings, A. F. Sarofim, and R. J. Pugmire, "Study of the Evolution of Soot from Various Fuels," Energy \& Fuels, vol. 19, no. 5, pp. 1804-1811, Sep. 2005.

[48] Y. Yang, A. L. Boehman, and R. J. Santoro, "A study of jet fuel sooting tendency using the threshold sooting index (TSI) model," Combust. Flame, vol. 149, no. 1-2, pp. 191-205, Apr. 2007.

[49] C. Mcenally and L. Pfefferle, "Improved sooting tendency measurements for aromatic hydrocarbons and 
their implications for naphthalene formation pathways," Combust. Flame, vol. 148, no. 4, pp. 210-222, Mar. 2007.

[50] M. Nakano, Y. Mandokoro, S. Kubo, and S. Yamazaki, "Effects of exhaust gas recirculation in homogeneous charge compression ignition engines," Int. J. Engine Res., vol. 1, no. 3, pp. 269-279, Jan. 2000 .

[51] R. Ogink and V. Golovitchev, "Gasoline HCCI Modeling: An Engine Cycle Simulation Code with a MultiZone Combustion Model," SAE Tech. Pap., May 2002.

[52] J. C. G. Andrae, P. Björnbom, R. F. Cracknell, and G. T. Kalghatgi, "Autoignition of toluene reference fuels at high pressures modeled with detailed chemical kinetics," Combust. Flame, vol. 149, no. 1-2, pp. 2-24, Apr. 2007.

[53] M. Chaos, Z. Zhao, A. Kazakov, P. Gokulakrishnan, M. Angioletti, and F. L. Dryer, "A PRF+Toluene Surrogate Fuel Model for Simulating Gasoline Kinetics," in 5th US Combustion Meeting, 2007.

[54] J. C. G. Andrae, T. Brinck, and G. T. Kalghatgi, "HCCI experiments with toluene reference fuels modeled by a semidetailed chemical kinetic model," Combust. Flame, vol. 155, no. 4, pp. 696-712, Dec. 2008.

[55] J. Anderlohr, R. Bounaceur, A. P. da Cruz, and F. Battin-Leclerc, "Modeling of autoignition and NO sensitization for the oxidation of IC engine surrogate fuels," Combust. Flame, vol. 156, no. 2, pp. 505-521, Feb. 2009.

[56] L. R. Cancino, M. Fikri, A. A. M. Oliveira, and C. Schulz, "Autoignition of gasoline surrogate mixtures at intermediate temperatures and high pressures: Experimental and numerical approaches," Proc. Combust. Inst., vol. 32, no. 1, pp. 501-508, 2009.

[57] Y. Sakai, A. Miyoshi, M. Koshi, and W. J. Pitz, "A kinetic modeling study on the oxidation of primary reference fuel-toluene mixtures including cross reactions between aromatics and aliphatics," Proc. Combust. Inst., vol. 32, no. 1, pp. 411-418, 2009.

[58] H. Machrafi, S. Cavadias, and J. Amouroux, "The development and experimental validation of a reduced ternary kinetic mechanism for the auto-ignition at HCCI conditions, proposing a global reaction path for ternary gasoline surrogates," Fuel Process. Technol., vol. 90, no. 2, pp. 247-263, Feb. 2009.

[59] K. Lee, Y. Kim, and K. Min, "Development of a reduced chemical kinetic mechanism for a gasoline surrogate for gasoline HCCI combustion," Combust. Theory Model., vol. 15, no. 1, pp. 107-124, Dec. 2010.

[60] Q. F. Zhang, Z. L. Zheng, Z. W. He, and Y. Wang, "Reduced Chemical Kinetic Model of Toluene Reference Fuels for HCCI Combustion," Acta Physico-Chimica Sin., vol. 27, no. 3, pp. 530-538, 2011.

[61] A. Raj, I. D. C. Prada, A. A. Amer, and S. H. Chung, "A reaction mechanism for gasoline surrogate fuels for large polycyclic aromatic hydrocarbons," Combust. Flame, vol. 159, no. 2, pp. 500-515, Feb. 2012.

[62] Y.-D. Liu, M. Jia, M.-Z. Xie, and B. Pang, "Development of a New Skeletal Chemical Kinetic Model of Toluene Reference Fuel with Application to Gasoline Surrogate Fuels for Computational Fluid Dynamics Engine Simulation,” Energy \& Fuels, vol. 27, no. 8, pp. 4899-4909, Aug. 2013.

[63] E. Ranzi, A. Frassoldati, A. Stagni, M. Pelucchi, A. Cuoci, and T. Faravelli, "Reduced Kinetic Schemes of Complex Reaction Systems: Fossil and Biomass-Derived Transportation Fuels," Int. J. Chem. Kinet., vol. 46, no. 9, pp. 512-542, Sep. 2014.

[64] K. E. Niemeyer and C.-J. Sung, "Mechanism reduction for multicomponent surrogates: A case study using toluene reference fuels," Combust. Flame, vol. 161, no. 11, pp. 2752-2764, Nov. 2014.

[65] Z. Zheng and Z. Lv, "A new skeletal chemical kinetic model of gasoline surrogate fuel with nitric oxide in HCCI combustion," Appl. Energy, vol. 147, pp. 59-66, Jun. 2015.

[66] H. Wang, M. Yao, Z. Yue, M. Jia, and R. D. Reitz, "A reduced toluene reference fuel chemical kinetic mechanism for combustion and polycyclic-aromatic hydrocarbon predictions," Combust. Flame, vol. 162, no. 6, pp. 2390-2404, Jun. 2015.

[67] Y. An, Y. Pei, J. Qin, H. Zhao, and X. Li, "Kinetic modeling of polycyclic aromatic hydrocarbons formation process for gasoline surrogate fuels," Energy Convers. Manag., vol. 100, pp. 249-261, Aug. 2015.

[68] M. Yahyaoui, N. Djebaili-Chaumeix, P. Dagaut, C.-E. Paillard, and S. Gail, "Experimental and modelling study of gasoline surrogate mixtures oxidation in jet stirred reactor and shock tube," Proc. Combust. Inst., vol. 31, no. 1, pp. 385-391, Jan. 2007.

[69] V. I. Golovitchev, C. A. Rinaldini, and G. Cantore, "Development and Application of Gasoline/EtOH Combustion Mechanism : Modeling of Direct Injection Ethanol Boosted Gasoline Engine(SI: Spark-Ignition Engine Combustion,General Session Papers)," Int. Symp. diagnostics Model. Combust. Intern. Combust. engines, vol. 2008, no. 7, pp. 251-257, Jul. 2008.

[70] T. Bieleveld, A. Frassoldati, A. Cuoci, T. Faravelli, E. Ranzi, U. Niemann, and K. Seshadri, "Experimental and kinetic modeling study of combustion of gasoline, its surrogates and components in laminar non- 
premixed flows," Proc. Combust. Inst., vol. 32, no. 1, pp. 493-500, 2009.

[71] C. Huang, V. Golovitchev, and A. Lipatnikov, "Chemical Model of Gasoline-Ethanol Blends for Internal Combustion Engine Applications," SAE Tech. Pap., Apr. 2010.

[72] M. Mehl, W. J. Pitz, C. K. Westbrook, and H. J. Curran, "Kinetic modeling of gasoline surrogate components and mixtures under engine conditions," Proc. Combust. Inst., vol. 33, no. 1, pp. 193-200, 2011.

[73] Y. Wang, M. Yao, and Z. Zheng, "A semi-detailed chemical kinetic model of a gasoline surrogate fuel for internal combustion engine applications," Fuel, vol. 113, pp. 347-356, Nov. 2013.

[74] P. Dirrenberger, P. A. Glaude, R. Bounaceur, H. Le Gall, A. P. da Cruz, A. A. Konnov, and F. BattinLeclerc, "Laminar burning velocity of gasolines with addition of ethanol," Fuel, vol. 115, pp. 162-169, Jan. 2014.

[75] K. E. Niemeyer and C.-J. Sung, "Reduced Chemistry for a Gasoline Surrogate Valid at Engine-Relevant Conditions," Energy \& Fuels, vol. 29, no. 2, pp. 1172-1185, Jan. 2015.

[76] Z. L. Zheng and Z. L. Liang, "Reduced Chemical Kinetic Model of a Gasoline Surrogate Fuel for HCCI Combustion," Acta Physico-Chimica Sin., vol. 31, no. 7, pp. 1265-1274, 2015.

[77] C. V. Naik, W. J. Pitz, C. K. Westbrook, M. Sjöberg, J. E. Dec, J. Orme, H. J. Curran, and J. M. Simmie, "Detailed Chemical Kinetic Modeling of Surrogate Fuels for Gasoline and Application to an HCCI Engine," SAE Tech. Pap., Oct. 2005.

[78] J. C. G. Andrae, "Development of a detailed kinetic model for gasoline surrogate fuels," Fuel, vol. 87, no. 10-11, pp. 2013-2022, Aug. 2008.

[79] B. G. Bunting, S. Eaton, C. V. Naik, K. V. Puduppakkam, C.-P. Chou, and E. Meeks, "A Comparison of HCCI Ignition Characteristics of Gasoline Fuels Using a Single-Zone Kinetic Model with a Five Component Surrogate Fuel," SAE Tech. Pap., Oct. 2008.

[80] J. C. G. Andrae and R. A. Head, "HCCI experiments with gasoline surrogate fuels modeled by a semidetailed chemical kinetic model," Combust. Flame, vol. 156, no. 4, pp. 842-851, Apr. 2009.

[81] L. R. Cancino, M. Fikri, A. A. M. Oliveira, and C. Schulz, "Ignition delay times of ethanol-containing multi-component gasoline surrogates: Shock-tube experiments and detailed modeling," Fuel, vol. 90, no. 3, pp. 1238-1244, Mar. 2011.

[82] B.-J. Zhong and D. Zheng, "A chemical mechanism for ignition and oxidation of multi-component gasoline surrogate fuels," Fuel, vol. 128, pp. 458-466, Jul. 2014.

[83] K. V. Puduppakkam, L. Liang, C. V. Naik, E. Meeks, and B. G. Bunting, "Combustion and Emissions Modeling of a Gasoline HCCI Engine Using Model Fuels," SAE Tech. Pap., Apr. 2009.

[84] K. V. Puduppakkam, C. V. Naik, C. Wang, and E. Meeks, "Validation Studies of a Detailed Kinetics Mechanism for Diesel and Gasoline Surrogate Fuels," SAE Tech. Pap., Apr. 2010.

[85] C. V. Naik, K. Puduppakkam, C. Wang, J. Kottalam, L. Liang, D. Hodgson, and E. Meeks, "Applying Detailed Kinetics to Realistic Engine Simulation: the Surrogate Blend Optimizer and Mechanism Reduction Strategies," SAE Int. J. Engines, vol. 3, no. 1, pp. 241-259, Apr. 2010.

[86] Y. Ra and R. D. Reitz, "A combustion model for IC engine combustion simulations with multi-component fuels," Combust. Flame, vol. 158, no. 1, pp. 69-90, Jan. 2011.

[87] K. Hashimoto, M. Koshi, A. Miyoshi, Y. Murakami, T. Oguchi, Y. Sakai, H. Ando, and K. Tsuchiya, "Development of Gasoline Combustion Reaction Model," SAE Tech. Pap., Apr. 2013.

[88] T. Lu and C. K. Law, "Toward accommodating realistic fuel chemistry in large-scale computations," Prog. Energy Combust. Sci., vol. 35, no. 2, pp. 192-215, Apr. 2009.

[89] H. Wang and M. Frenklach, "Detailed reduction of reaction mechanisms for flame modeling," Combust. Flame, vol. 87, no. 3-4, pp. 365-370, Dec. 1991.

[90] T. Lu and C. K. Law, "A directed relation graph method for mechanism reduction," Proc. Combust. Inst., vol. 30, no. 1, pp. 1333-1341, Jan. 2005.

[91] A. Patel, S.-C. Kong, and R. D. Reitz, "Development and Validation of a Reduced Reaction Mechanism for HCCI Engine Simulations," SAE Tech. Pap., Mar. 2004.

[92] T. Nagy and T. Turányi, "Reduction of very large reaction mechanisms using methods based on simulation error minimization," Combust. Flame, vol. 156, no. 2, pp. 417-428, Feb. 2009.

[93] X. Cheng, H. K. Ng, S. Gan, and J. H. Ho, "Advances in Computational Fluid Dynamics (CFD) Modeling of In-Cylinder Biodiesel Combustion,” Energy \& Fuels, vol. 27, no. 8, pp. 4489-4506, Aug. 2013.

[94] T. Turányi and A. S. Tomlin, Analysis of Kinetic Reaction Mechanisms. Berlin: Springer Berlin Heidelberg, 2014.

[95] R. Sivaramakrishnan, R. S. Tranter, and K. Brezinsky, "A high pressure model for the oxidation of toluene," Proc. Combust. Inst., vol. 30, no. 1, pp. 1165-1173, Jan. 2005. 
[96] H. Curran, P. Gaffuri, W. J. Pitz, and C. K. Westbrook, "A comprehensive modeling study of iso-octane oxidation," Combust. Flame, vol. 129, no. 3, pp. 253-280, May 2002.

[97] S. D. Klotz, K. Brezinsky, and I. Glassman, "Modeling the combustion of toluene-butane blends," Symp. Combust., vol. 27, no. 1, pp. 337-344, Jan. 1998.

[98] Y. Sakai, H. Ozawa, T. Ogura, A. Miyoshi, M. Koshi, and W. J. Pitz, "Effects of Toluene Addition to Primary Reference Fuel at High Temperature," SAE Tech. Pap., Oct. 2007.

[99] C. A. Schuetz and M. Frenklach, "Nucleation of soot: Molecular dynamics simulations of pyrene dimerization," Proc. Combust. Inst., vol. 29, no. 2, pp. 2307-2314, Jan. 2002.

[100] H. Richter and J. . Howard, "Formation of polycyclic aromatic hydrocarbons and their growth to soot-a review of chemical reaction pathways," Prog. Energy Combust. Sci., vol. 26, no. 4-6, pp. 565-608, Aug. 2000.

[101] G. Blanquart, P. Pepiot-Desjardins, and H. Pitsch, "Chemical mechanism for high temperature combustion of engine relevant fuels with emphasis on soot precursors," Combust. Flame, vol. 156, no. 3, pp. 588-607, Mar. 2009.

[102] C. Marchal, J.-L. Delfau, C. Vovelle, G. Moréac, C. Mounaı"m-Rousselle, and F. Mauss, "Modelling of aromatics and soot formation from large fuel molecules," Proc. Combust. Inst., vol. 32, no. 1, pp. 753-759, 2009.

[103] D. Cohn, L. Bromberg, and J. Heywood, "Direct Injection Ethanol Boosted Gasoline Engines: Biofuel Leveraging For Cost Effective Reduction of Oil Dependence and CO2 Emissions," 2005.

[104] L. Cai and H. Pitsch, "Mechanism optimization based on reaction rate rules," Combust. Flame, vol. 161, no. 2, pp. 405-415, Feb. 2014.

[105] C. V. Naik, K. Puduppakkam, and E. Meeks, "Modeling the Detailed Chemical Kinetics of NOx Sensitization for the Oxidation of a Model fuel for Gasoline," SAE Int. J. Fuels Lubr., vol. 3, no. 1, pp. 556566, Apr. 2010.

[106] Y. Shi, H.-W. Ge, and R. D. Reitz, Computational Optimization of Internal Combustion Engines. London: Springer London, 2011.

[107] M. C. Drake and D. C. Haworth, "Advanced gasoline engine development using optical diagnostics and numerical modeling," Proc. Combust. Inst., vol. 31, no. 1, pp. 99-124, Jan. 2007.

[108] H. Li, "CFD modelling study of sprays and combustion of gasoline and DMF in direct injection gasoline engines," The University of Birmingham, 2013.

[109] A. Gill, E. Gutheil, and J. Warnatz, "Numerical Investigation of the Combustion Process in a DirectInjection Stratified Charge Engine," Combust. Sci. Technol., vol. 115, no. 4-6, pp. 317-333, Jun. 1996.

[110] J. Kech, J. Reissing, J. Gindele, and U. Spicher, "Analyses of the Combustion Process in a Direct Injection Gasoline Engine," in The Fourth International Symposium COMODIA 98, 1998, pp. 287-292.

[111] J. Duclos and M. Zolver, "3D Modeling of Intake, Injection and Combustion in a DI-SI Engine under Homogeneous and Stratified Operating Conditions," in The Fourth International Symposium COMODIA 98, 1998, pp. 335-340.

[112] R. Tatschl and H. Riediger, "PDF Modelling of Stratified Charge SI Engine Combustion," SAE Tech. Pap., May 1998.

[113] S. Henriot, A. Chaouche, E. Cheve, and J. M. Duclos, "CFD Aided Development of a Si-Di Engine," Oil Gas Sci. Technol., vol. 54, no. 2, pp. 279-286, Mar. 1999.

[114] J. P. Duclos, M. Zolver, and T. Baritaud, "3D Modeling of Combustion for DI-SI Engines," Oil Gas Sci. Technol., vol. 54, no. 2, pp. 259-264, Mar. 1999.

[115] L. Fan, G. Li, Z. Han, and R. D. Reitz, "Modeling Fuel Preparation and Stratified Combustion in a Gasoline Direct Injection Engine," SAE Tech. Pap., Mar. 1999.

[116] T. Georjon, E. Bourguignon, T. Duverger, B. Delhaye, and P. Voisard, "Characteristics of Mixture Formation and Combustion in a Spray-Guided Concept Gasoline Direct Injection Engine: An Experimental and Numerical Approach," SAE Tech. Pap., Mar. 2000.

[117] R. Tatschl, H. Riediger, C. v. Künsberg Sarre, N. Putz, and F. Kickinger, "Rapid Meshing and Advanced Physical Modeling for Gasoline DI Engine Application," in International Multidimensional Modeling User's Group Meeting at the SAE Congress, 2000.

[118] J. Hélie, J.-M. Duclos, T. Baritaud, T. Poinsot, and A. Trouvé, "Influence of Mixture Fluctuations on Combustion in Direct Injection Spark Ignition Engines Simulations," SAE Tech. Pap., Mar. 2001.

[119] Y. Nomura, H. Miyagawa, T. Fujikawa, T. Tomoda, M. Kubota, and S. Abe, "Numerical Study of Mixture Formation and Combustion Processes in a Direct Injection Gasoline Engine with Fan-Shaped Spray," SAE Tech. Pap., Mar. 2001. 
[120] J. Wallesten, A. Lipatnikov, and J. Chomiak, "Modeling of stratified combustion in a direct-ignition, sparkignition engine accounting for complex chemistry," Proc. Combust. Inst., vol. 29, no. 1, pp. 703-709, Jan. 2002.

[121] M. Castagné, J. P. Dumas, S. Henriot, and P. Pierre, "Use of Advanced Tools for the Analysis of Gasoline Direct Injection Engines,” Oil Gas Sci. Technol., vol. 58, no. 1, pp. 79-100, Jan. 2003.

[122] O. Colin, A. Benkenida, and C. Angelberger, "3D Modeling of Mixing, Ignition and Combustion Phenomena in Highly Stratified Gasoline Engines," Oil Gas Sci. Technol., vol. 58, no. 1, pp. 47-62, Jan. 2003.

[123] T. Wakisaka and T. Esumi, "CFD Simulation of Mixture Formation and Combustion Processes in a DirectInjection Gasoline Engine Using a GTT Code," SAE Tech. Pap., May 2003.

[124] Z. Tan, S.-C. Kong, and R. D. Reitz, "Modeling Premixed and Direct Injection SI Engine Combustion Using the G-Equation Model," SAE Tech. Pap., May 2003.

[125] B. P. Vanzieleghem, V. Sick, H. G. Im, and D. N. Assanis, "Modeling of Gasoline Direct Injection Mixture Formation with KIVA-3V and Validation with Optical Engine Planar Laser Induced Fluorescence Measurements : Development of an Extended Coherent Flamelet Model (S.I. Engines, G.D.I. Modelling)," Int. Symp. diagnostics Model. Combust. Intern. Combust. engines, vol. 2004, no. 6, pp. 537-544, Aug. 2004.

[126] M. C. Drake, T. D. Fansler, and A. M. Lippert, "Stratified-charge combustion: modeling and imaging of a spray-guided direct-injection spark-ignition engine," Proc. Combust. Inst., vol. 30, no. 2, pp. 2683-2691, Jan. 2005.

[127] J. Gao, D. M. Jiang, Z. H. Huang, and X. Bin Wang, "Numerical study on spray and mixture stratified combustion in a direct injection gasoline engine," Neiranji Xuebao/Transactions CSICE (Chinese Soc. Intern. Combust. Engines), vol. 23, no. 4, pp. 297-306, 2005.

[128] L. Olmo and J. Thornton, "CFD Analysis of Mixture Formation and Combustion Process for High Performance DI Gasoline Engine," SAE Tech. Pap., Apr. 2005.

[129] J. Liu, J. Gong, L. Cai, L. Tan, X. Ni, and W. Gao, "Multi-dimensional Simulation of Air/Fuel Premixing and Stratified Combustion in a Gasoline Direct Injection Engine with Combustion Chamber Bowl Offset," 2006.

[130] R. Rotondi, "Modeling Mixture Formation in a Gasoline Direct Injection Engine," J. Appl. Mech., vol. 73, no. 6, p. 931, Nov. 2006.

[131] J. Bohbot, C. Chryssakis, and M. Miche, "Simulation of a 4-Cylinder Turbocharged Gasoline Direct Injection Engine Using a Direct Temporal Coupling Between a 1D Simulation Software and a 3D Combustion Code," SAE Tech. Pap., Oct. 2006.

[132] L. Liang and R. D. Reitz, "Spark Ignition Engine Combustion Modeling Using a Level Set Method with Detailed Chemistry," SAE Tech. Pap., Apr. 2006.

[133] S.-J. Kim, Y.-N. Kim, and J.-H. Lee, "Analysis of the In-Cylinder Flow, Mixture Formation and Combustion Processes in a Spray-Guided GDI Engine," SAE Tech. Pap., Apr. 2008.

[134] S. Yang and R. D. Reitz, "Integration of a Continuous Multi-Component Fuel Evaporation Model with an Improved G-Equation Combustion and Detailed Chemical Kinetics Model with Application to GDI Engines," SAE Tech. Pap., Apr. 2009.

[135] R. Dahms, T. D. Fansler, M. C. Drake, T.-W. Kuo, A. M. Lippert, and N. Peters, "Modeling ignition phenomena in spray-guided spark-ignited engines," Proc. Combust. Inst., vol. 32, no. 2, pp. 2743-2750, 2009.

[136] Y. Bai, Z. Wang, S. Shuai, and J. Wang, "Three-Dimensional Numerical Simulation of Spray, Mixed Gas Formation and Combustion Process for Gasoline Direct Injection Engine," J. Combust. Sci. Technol., vol. 16, no. 2, 2010.

[137] R. N. Dahms, M. C. Drake, R. O. Grover, A. S. Solomon, and T. D. Fansler, "Detailed Simulations of Stratified Ignition and Combustion Processes in a Spray-Guided Gasoline Engine using the SparkCIMM/GEquation Modeling Framework," SAE Int. J. Engines, vol. 5, no. 2, pp. 141-161, Apr. 2012.

[138] X. Yang, A. Solomon, and T.-W. Kuo, "Ignition and Combustion Simulations of Spray-Guided SIDI Engine using Arrhenius Combustion with Spark-Energy Deposition Model," SAE Tech. Pap., Apr. 2012.

[139] S. D. Givler, M. Raju, E. Pomraning, P. K. Senecal, N. Salman, and R. Reese, "Gasoline Combustion Modeling of Direct and Port-Fuel Injected Engines using a Reduced Chemical Mechanism," SAE Tech. Pap., Apr. 2013.

[140] M. Costa, L. Marchitto, S. S. Merola, and U. Sorge, "Study of mixture formation and early flame development in a research GDI (gasoline direct injection) engine through numerical simulation and UVdigital imaging," Energy, vol. 77, pp. 88-96, Dec. 2014. 
[141] T. Kim, J. Song, and S. Park, "Effects of turbulence enhancement on combustion process using a double injection strategy in direct-injection spark-ignition (DISI) gasoline engines," Int. J. Heat Fluid Flow, vol. 56, pp. 124-136, Dec. 2015.

[142] C. K. Westbrook, Y. Mizobuchi, T. J. Poinsot, P. J. Smith, and J. Warnatz, "Computational combustion," Proc. Combust. Inst., vol. 30, no. 1, pp. 125-157, Jan. 2005.

[143] R. W. Bilger, S. B. Pope, K. N. C. Bray, and J. F. Driscoll, "Paradigms in turbulent combustion research," Proc. Combust. Inst., vol. 30, no. 1, pp. 21-42, Jan. 2005.

[144] B. E. Launder and D. B. Spalding, "The numerical computation of turbulent flows," Comput. Methods Appl. Mech. Eng., vol. 3, no. 2, pp. 269-289, Mar. 1974.

[145] V. Patel, W. Rodi, and G. Scheuerer, "Turbulence models for near-wall and low Reynolds number flows - A review," AIAA J., vol. 23, no. 9, pp. 1308-1319, May 1985.

[146] P. A. Durbin, "Separated flow computations with the k-epsilon-v-squared model," AIAA J., vol. 33, no. 4, pp. 659-664, Apr. 1995.

[147] V. Yakhot and L. M. Smith, "The renormalization group, the $\varepsilon$-expansion and derivation of turbulence models," J. Sci. Comput., vol. 7, no. 1, pp. 35-61, Mar. 1992.

[148] B. E. Launder, G. J. Reece, and W. Rodi, "Progress in the development of a Reynolds-stress turbulence closure," J. Fluid Mech., vol. 68, no. 03, pp. 537-566, Apr. 1975.

[149] H. Pitsch, "Large-Eddy Simulation of Turbulent Combustion," Annu. Rev. Fluid Mech., vol. 38, no. 1, pp. 453-482, Jan. 2006.

[150] S. B. Pope, Turbulent Flows. London: Cambridge University Press, 2000.

[151] B. Johansson, "Cycle to Cycle Variations in S.I. Engines - The Effects of Fluid Flow and Gas Composition in the Vicinity of the Spark Plug on Early Combustion," SAE Tech. Pap., Oct. 1996.

[152] G. . Faeth, L.-P. Hsiang, and P.-K. Wu, "Structure and breakup properties of sprays," Int. J. Multiph. Flow, vol. 21, pp. 99-127, Dec. 1995.

[153] C. . Hirt and B. . Nichols, "Volume of fluid (VOF) method for the dynamics of free boundaries," J. Comput. Phys., vol. 39, no. 1, pp. 201-225, Jan. 1981.

[154] M. Sanjosé, J. M. Senoner, F. Jaegle, B. Cuenot, S. Moreau, and T. Poinsot, "Fuel injection model for Euler-Euler and Euler-Lagrange large-eddy simulations of an evaporating spray inside an aeronautical combustor," Int. J. Multiph. Flow, vol. 37, no. 5, pp. 514-529, Jun. 2011.

[155] J. C. Beck and A. P. Watkins, "The droplet number moments approach to spray modelling: The development of heat and mass transfer sub-models," Int. J. Heat Fluid Flow, vol. 24, no. 2, pp. 242-259, Apr. 2003.

[156] G. M. Faeth, "Spray combustion phenomena," Symp. Combust., vol. 26, no. 1, pp. 1593-1612, Jan. 1996.

[157] E. de Villiers, A. D. Gosman, and H. G. Weller, "Large Eddy Simulation of Primary Diesel Spray Atomization," SAE Tech. Pap., Mar. 2004.

[158] V. Levich, Physicochemical hydrodynamics. New Jersey: Prentice-Hall, 1962.

[159] M. J. McCarthy and N. A. Molloy, "Review of stability of liquid jets and the influence of nozzle design," Chem. Eng. J., vol. 7, no. 1, pp. 1-20, Jan. 1974.

[160] R. D. Reitz and F. V. Bracco, "Mechanism of atomization of a liquid jet," Phys. Fluids, vol. 25, no. 10, p. 1730, Oct. 1982.

[161] P. Jenny, D. Roekaerts, and N. Beishuizen, "Modeling of turbulent dilute spray combustion," Prog. Energy Combust. Sci., vol. 38, no. 6, pp. 846-887, Dec. 2012.

[162] N. Zeoli and S. Gu, "Numerical modelling of droplet break-up for gas atomisation," Comput. Mater. Sci., vol. 38, no. 2, pp. 282-292, Dec. 2006.

[163] C. Baumgarten, Mixture Formation in Internal Combustion Engines. New Delhi: Springer-Verlag Berlin Heidelberg, 2006.

[164] J. Qian and C. K. Law, "Regimes of coalescence and separation in droplet collision," J. Fluid Mech., vol. 331, pp. 59-80, Jan. 1997.

[165] G. Godsave, "Studies of the Combustion of Drops in a Fuel Spray-The Burning of Single Drops of Fuel," in Fourth Symposium (International) on Combustion, 1953, pp. 818-830.

[166] D. Spalding, "The Combustion of Liquid Fuels," in Fourth Symposium (International) on Combustion, 1953, pp. 847-864.

[167] L. Zhang and S.-C. Kong, "Modeling of multi-component fuel vaporization and combustion for gasoline and diesel spray," Chem. Eng. Sci., vol. 64, no. 16, pp. 3688-3696, Aug. 2009.

[168] R. Lindgren and I. Denbratt, "Modeling Gasoline Spray-Wall Interactions and Comparison to Experimental Data," SAE Tech. Pap., Oct. 2004. 
[169] G. E. Cossali, A. Coghe, and M. Marengo, "The impact of a single drop on a wetted solid surface," Exp. Fluids, vol. 22, no. 6, pp. 463-472, Apr. 1997.

[170] R. D. Reitz and R. Diwakar, "Effect of Drop Breakup on Fuel Sprays," SAE Tech. Pap., Feb. 1986.

[171] R. D. Reitz and R. Diwakar, "Structure of High-Pressure Fuel Sprays," SAE Tech. Pap., Feb. 1987.

[172] C. Huang and A. Lipatnikov, "Modelling of Gasoline and Ethanol Hollow-Cone Sprays Using OpenFOAM," SAE Tech. Pap., Aug. 2011.

[173] Y. Yi and C. M. DeMinco, "Numerical Investigation of Mixture Preparation in a GDI Engine," SAE Tech. Pap., Oct. 2006.

[174] A. Lipatnikov, Fundamentals of Premixed Turbulent Combustion. Boca Raton: CRC Press, 2012.

[175] D. B. Spalding, "Mixing and chemical reaction in steady confined turbulent flames," Symp. Combust., vol. 13, no. 1, pp. 649-657, Jan. 1971.

[176] J. Abraham, F. V. Bracco, and R. D. Reitz, "Comparisons of computed and measured premixed charge engine combustion," Combust. Flame, vol. 60, no. 3, pp. 309-322, Jun. 1985.

[177] K. N. C. Bray, "Turbulent flows with premixed reactants," in Turbulent Reacting Flows, P. Libby and F. Williams, Eds. Berlin: Springer-Verlag, 1980, pp. 115-183.

[178] F. E. Marble and J. E. Broadwell, "The Coherent Flame Model for Turbulent Chemical Reactions," 1977.

[179] N. Peters, Turbulent Combustion. Cambridge: Cambridge University Press, 2000.

[180] A. N. Lipatnikov and J. Chomiak, "Turbulent flame speed and thickness: phenomenology, evaluation, and application in multi-dimensional simulations," Prog. Energy Combust. Sci., vol. 28, no. 1, pp. 1-74, Jan. 2002.

[181] J. W. Dold, "Flame propagation in a nonuniform mixture: Analysis of a slowly varying Triple Flame," Combust. Flame, vol. 76, no. 1, pp. 71-88, Apr. 1989.

[182] T. Koch, K. Schänzlin, and K. Boulouchos, "Characterization and Phenomenological Modeling of Mixture Formation and Combustion in a Direct Injection Spark Ignition Engine," SAE Tech. Pap., Mar. 2002.

[183] J. Andersson, M. Keenan, and K. Åkerman, "GDI Particles - Legislation, Current Levels And Control," in Cambridge Particle Meeting, 2009.

[184] L. Ntziachristos, A. Mamakos, Z. Samaras, U. Mathis, M. Mohr, N. Thompson, R. Stradling, L. Forti, and C. de Serves, "Overview of the European 'Particulates' Project on the Characterization of Exhaust Particulate Emissions From Road Vehicles: Results for Light-Duty Vehicles," SAE Tech. Pap., Jun. 2004.

[185] O. I. Smith, "Fundamentals of soot formation in flames with application to diesel engine particulate emissions," Prog. Energy Combust. Sci., vol. 7, no. 4, pp. 275-291, Jan. 1981.

[186] I. Glassman, "Soot formation in combustion processes," Symp. Combust., vol. 22, no. 1, pp. 295-311, Jan. 1989.

[187] R. A. Dobbins and H. Subramaniasivam, "Soot Precursor Particles in Flames," in Soot Formation in Combustion, H. Bockhorn, Ed. Berlin: Springer Berlin Heidelberg, 1994, pp. 290-301.

[188] P. L.Walker, L. G. Austin, and S. P. Nandi., Chemistry and Physics of Carbon, 2nd ed. New York: Marcel Dekker, 1966.

[189] B. . Stanmore, J. . Brilhac, and P. Gilot, "The oxidation of soot: a review of experiments, mechanisms and models," Carbon N. Y., vol. 39, no. 15, pp. 2247-2268, Dec. 2001.

[190] M. Frenklach, "Reaction mechanism of soot formation in flames," Phys. Chem. Chem. Phys., vol. 4, no. 11, pp. 2028-2037, May 2002.

[191] I. Glassman, Combustion, 3rd ed. San Diego, CA: Academic Press, 1996.

[192] S. Mosbach, M. S. Celnik, A. Raj, M. Kraft, H. R. Zhang, S. Kubo, and K.-O. Kim, "Towards a detailed soot model for internal combustion engines," Combust. Flame, vol. 156, no. 6, pp. 1156-1165, Jun. 2009.

[193] M. Frenklach and H. Wang, "Detailed Mechanism and Modeling of Soot Particle Formation," in Soot Formation in Combustion, vol. 59, H. Bockhorn, Ed. Berlin, Heidelberg: Springer Berlin Heidelberg, 1994.

[194] W. Bartok and A. F. Sarofim, Eds., Fossil Fuel Combustion: A Source Book. California: Wiley-Interscience, 1991.

[195] H. Kellerer, R. Koch, and S. Wittig, "Measurements of the growth and coagulation of soot particles in a high-pressure shock tube," Combust. Flame, vol. 120, no. 1-2, pp. 188-199, Jan. 2000.

[196] I. M. Kennedy, "Models of soot formation and oxidation," Prog. Energy Combust. Sci., vol. 23, no. 2, pp. 95-132, Jan. 1997.

[197] B. R. Graskow, D. B. Kittelson, M. R. Ahmadi, and J. E. Morris, "Exhaust Particulate Emissions from a Direct Injection Spark Ignition Engine," SAE Tech. Pap., Mar. 1999.

[198] P. Price, R. Stone, T. Collier, and M. Davies, "Particulate Matter and Hydrocarbon Emissions Measurements: Comparing First and Second Generation DISI with PFI in Single Cylinder Optical Engines," 
SAE Tech. Pap., Apr. 2006.

[199] T. L. Barone, J. M. E. Storey, A. D. Youngquist, and J. P. Szybist, "An analysis of direct-injection sparkignition (DISI) soot morphology," Atmos. Environ., vol. 49, pp. 268-274, Mar. 2012.

[200] D. Kittelson, "Ultrafine Particle Formation Mechanisms," in South Coast Air Quality Management District Conference on Ultrafine Particles: The Science, Technology, and Policy Issues, 2006.

[201] E. Stevens and R. Steeper, "Piston Wetting in an Optical DISI Engine: Fuel Films, Pool Fires, and Soot Generation," SAE Tech. Pap., Mar. 2001.

[202] M. C. Drake, T. D. Fansler, A. S. Solomon, and G. A. Szekely, "Piston Fuel Films as a Source of Smoke and Hydrocarbon Emissions from a Wall-Controlled Spark-Ignited Direct-Injection Engine," SAE Tech. Pap., Mar. 2003.

[203] H. Fujimoto, "Study on the oil dilution of a DI gasoline engine - 1st report: dilution on the cylinder wall," in Proceedings of the JSAE Spring Convention, 1999.

[204] J. Appel, H. Bockhorn, and M. Frenklach, "Kinetic modeling of soot formation with detailed chemistry and physics: laminar premixed flames of C2 hydrocarbons," Combust. Flame, vol. 121, no. 1-2, pp. 122-136, Apr. 2000.

[205] M. E. Mueller, G. Blanquart, and H. Pitsch, "A joint volume-surface model of soot aggregation with the method of moments," Proc. Combust. Inst., vol. 32, no. 1, pp. 785-792, 2009.

[206] M. Balthasar and M. Kraft, "A stochastic approach to calculate the particle size distribution function of soot particles in laminar premixed flames," Combust. Flame, vol. 133, no. 3, pp. 289-298, May 2003.

[207] F. Gelbard and J. H. Seinfeld, "Simulation of multicomponent aerosol dynamics," J. Colloid Interface Sci., vol. 78, no. 2, pp. 485-501, Dec. 1980.

[208] K. Netzell, H. Lehtiniemi, and F. Mauss, "Calculating the soot particle size distribution function in turbulent diffusion flames using a sectional method," Proc. Combust. Inst., vol. 31, no. 1, pp. 667-674, Jan. 2007.

[209] M. Frenklach and S. J. Harris, "Aerosol dynamics modeling using the method of moments," J. Colloid Interface Sci., vol. 118, no. 1, pp. 252-261, Jul. 1987.

[210] J. Wallesten, A. Lipatnikov, and J. Chomiak, "Simulations of Fuel/Air Mixing, Combustion, and Pollutant Formation in a Direct Injection Gasoline Engine," SAE Tech. Pap., Mar. 2002.

[211] J. Etheridge, S. Mosbach, M. Kraft, H. Wu, and N. Collings, "Modelling soot formation in a DISI engine," Proc. Combust. Inst., vol. 33, no. 2, pp. 3159-3167, Jan. 2011.

[212] H. Kwon, H. Choi, J. Kim, and K. Min, "Combustion and emission modelling of a direct-injection sparkignition engine by combining flamelet models for premixed and diffusion flames," Combust. Theory Model., vol. 16, no. 6, pp. 1089-1108, Dec. 2012.

[213] J. Kim, G. Kim, H. Lee, and K. Min, "Numerical Analysis of Pollutant Formation in Direct-Injection SparkIgnition Engines by Incorporating the G- Equation with a Flamelet Library," SAE Tech. Pap., Apr. 2014.

[214] C. V. Naik, L. Liang, K. Puduppakkam, and E. Meeks, "Simulation and Analysis of In-Cylinder Soot Formation in a Gasoline Direct-Injection Engine Using a Detailed Reaction Mechanism," SAE Tech. Pap., Apr. 2014.

[215] L. Liang, C. V. Naik, K. V. Puduppakkam, A. U. Modak, and E. Meeks, "Application of Detailed SootParticle Model to Simulations of Fundamental Spray Experiments and GDI Engine," in International Multidimensional Engine Modeling User's Group Meeting, 2014.

[216] B. Wang, S. Mosbach, S. Schmutzhard, S. Shuai, Y. Huang, and M. Kraft, "Modelling soot formation from wall films in a gasoline direct injection engine using a detailed population balance model," Appl. Energy, vol. 163, pp. 154-166, Feb. 2016.

[217] A. Fusco, A. Knox-Kelecy, and D. Foster, "Application of a phenomenological soot model to diesel engine combustion," Int. Symp. COMODIA, 1994.

[218] H. El-Asrag, T. Lu, C. Law, and S. Menon, "Simulation of soot formation in turbulent premixed flames," Combust. Flame, vol. 150, no. 1-2, pp. 108-126, Jul. 2007.

[219] K. V. Puduppakkam, A. U. Modak, C. V. Naik, J. Camacho, H. Wang, and E. Meeks, "A Soot Chemistry Model That Captures Fuel Effects," in ASME Turbo Expo 2014: Turbine Technical Conference and Exposition, 2014.

[220] K. Puduppakkam, A. Modak, and C. Naik, "Progress in Predicting Soot Particle Numbers in CFD Simulations of GDI and Diesel Engines," in International Multidimensional Engine Modeling User's Group Meeting, 2015.

[221] G. Vishwanathan and R. D. Reitz, "Development of a Practical Soot Modeling Approach and Its Application to Low-Temperature Diesel Combustion," Combust. Sci. Technol., vol. 182, no. 8, pp. 1050-1082, Jul. 2010.

[222] Q. Jiao and R. D. Reitz, "Modeling of Equivalence Ratio Effects on Particulate Formation in a Spark- 
Ignition Engine under Premixed Conditions," SAE Tech. Pap., Apr. 2014.

[223] Q. Jiao and R. D. Reitz, "The Effect of Operating Parameters on Soot Emissions in GDI Engines," SAE Int. J. Engines, vol. 8, no. 3, pp. 2015-01-1071, Apr. 2015. 